\title{
An evaluation of Arctic cloud and radiation processes during the SHEBA year: simulation results from eight Arctic regional climate models
}

\author{
K. Wyser · C. G. Jones · P. Du · E. Girard · U. Willén · J. Cassano · J. H. Christensen • \\ J. A. Curry $\cdot$ K. Dethloff $\cdot$ J.-E. Haugen $\cdot$ D. Jacob $\cdot$ M. Køltzow $\cdot$ R. Laprise · \\ A. Lynch $\cdot$ S. Pfeifer $\cdot$ A. Rinke $\cdot$ M. Serreze $\cdot$ M. J. Shaw $\cdot$ M. Tjernström $\cdot$ M. Zagar
}

Received: 27 November 2006/Accepted: 15 May 2007/Published online: 27 June 2007

(C) Springer-Verlag 2007

\begin{abstract}
Eight atmospheric regional climate models (RCMs) were run for the period September 1997 to October 1998 over the western Arctic Ocean. This period was coincident with the observational campaign of the Surface Heat Budget of the Arctic Ocean (SHEBA) project. The RCMs shared common domains, centred on the SHEBA observation camp, along with a common model horizontal resolution, but differed in their vertical structure and physical parameterizations. All RCMs used the same lateral and surface boundary conditions. Surface downwelling solar and terrestrial radiation, surface albedo, vertically integrated water vapour, liquid water path and cloud cover from each model are evaluated against the SHEBA observation data. Downwelling surface radiation, vertically integrated water vapour and liquid water path are reasonably well simulated at monthly and daily timescales in the
\end{abstract}

K. Wyser $(\bowtie) \cdot$ U. Willén · M. Tjernström · M. Zagar

Rossby Centre, SMHI, Norrköping, Sweden

e-mail: Klaus.Wyser@smhi.se

C. G. Jones · P. Du · E. Girard · R. Laprise

Canadian Regional Climate Modelling and Diagnostics

Network, Université du Québec à Montréal,

Montreal, Canada

K. Dethloff · A. Rinke

Alfred Wegener Institute for Polar and Marine Research,

Research Unit, Potsdam, Germany

J. Cassano · M. Serreze $\cdot$ M. J. Shaw

Cooperative Institute for Research in Environmental Sciences and Department of Atmospheric and Oceanic Sciences,

University of Colorado, Boulder, CO, USA

J. H. Christensen

Danish Meteorological Institute, Copenhagen, Denmark model ensemble mean, but with considerable differences among individual models. Simulated surface albedos are relatively accurate in the winter season, but become increasingly inaccurate and variable in the melt season, thereby compromising the net surface radiation budget. Simulated cloud cover is more or less uncorrelated with observed values at the daily timescale. Even for monthly averages, many models do not reproduce the annual cycle correctly. The inter-model spread of simulated cloud-cover is very large, with no model appearing systematically superior. Analysis of the co-variability of terms controlling the surface radiation budget reveal some of the key processes requiring improved treatment in Arctic RCMs. Improvements in the parameterization of cloud amounts and surface albedo are most urgently needed to improve the overall performance of RCMs in the Arctic. 
Keywords Arctic climate - Cloud-radiation interaction . Cloud cover - Longwave radiation - Shortwave radiation . Surface albedo

\section{Introduction}

Clouds play a key role in regulating the surface energy budget of the Arctic Ocean (Curry et al. 1993; Intrieri et al. 2002b) and are, therefore, important indirect controls on the evolution of Arctic sea-ice and the sea-ice/snow albedo feedback (Thorndike 1992). Due to the unique conditions in the Arctic (e.g. extreme low temperatures and water vapour mixing ratios, highly reflective sea-ice/snow surfaces, low-level inversions and the absence of solar radiation for extended periods) the macrophysical and microphysical processes controlling cloud formation and cloud-radiation interaction are complex and unique. This has led to difficulties both in simulating Arctic cloud phenomena as well as observing clouds in the Arctic (Wyser and Jones 2005; Uttal et al. 2002).

During winter the Arctic atmospheric boundary layer is extremely stable. As a result, deep surface-based temperature inversions are frequent (Serreze et al. 1992). This situation leads to extensive low-level cloudiness with significant amounts of cloud ice present. Furthermore, the combination of a low concentration of cloud ice forming nuclei, slow radiative cooling of the Arctic air mass and very low specific humidity leads to a high frequency of lowlevel large ice crystals, commonly referred to as "diamond dust" (Curry et al. 1990; Girard and Blanchet 2001). In the summer, multiple layers of clouds are common with upper level cloud layers often being decoupled from the surface. During the transition seasons, mixed-phase boundary layer clouds, topped by a thin inversion layer are the predominant cloud type (Shupe et al. 2006; Pinto et al. 1997). These large seasonal variations in cloud types, along with high solar zenith angles and a reflective surface make the simulation of Arctic clouds and radiation a challenge.

An early intercomparison of 19 General Circulation Models (GCMs) indicated a general disagreement between models, of as much as $50 \%$, with respect to seasonal mean cloud cover over the Arctic. A number of models even simulated the annual cycle of cloud cover completely out of phase with observations (Chen et al. 1995; Tao et al. 1996). A more recent study showed some improvement in the simulation of Arctic cloud amounts, although surface radiation fluxes still varied widely between models (Walsh et al. 2002). These findings point to the need for further improvement in the representation of the Arctic surface radiation budget in climate models.

The main disadvantage in using GCMs to improve cloud and radiation parameterisations in the Arctic is that the local, simulated thermodynamic state of the Arctic atmosphere is heavily influenced by GCM errors remote to the Arctic region (e.g. biases in the driving sea-level pressure fields or mid-latitude storm-track errors). These errors propagate into the Arctic and compromise the quality of the simulated Arctic thermodynamic structure, within which cloud and radiation parameterisations must operate. This situation makes it difficult to develop and evaluate Arctic parameterization schemes in the correct thermodynamic parameter space within a GCM. A sensible comparison of GCM simulated clouds and radiation, against localised, time-limited observations over the Arctic is made difficult by the divergence of the large-scale Arctic-atmospheric state due to these external influences.

Single-column models (SCMs) are valuable tools to test and improve parameterizations of physical processes. They are fast and practical to explore large parameter spaces, and can use prescribed dynamical forcing to constrain the SCM atmosphere to follow observed conditions. This can be extremely useful for developing cloud parameterisations (e.g. Duynkerke et al. 2004; Lenderink et al. 2004). Curry and coauthors (2000) analysed a suite of SCMs that simulated periods of the First ISCCP Regional ExperimentArctic Clouds Experiment (FIRE-ACE) during May 1998. A majority of these SCMs underestimated the observed liquid water path and low cloud amounts for this period.

While SCMs can be constrained by application of observed or analysed large-scale forcing, they do not allow modelled cloud and radiation processes to interact with the simulated dynamics. Furthermore, it is often difficult to accurately define the horizontal resolution of an SCM, normally defined by the spatial scale of the prescribed dynamical forcing, making the formal separation of resolved and subgrid scales difficult.

Regional Climate Models (RCMs) offer a potential middle road between GCMs and SCMs. Careful design of an RCM domain and specification of the Lateral Boundary Conditions (LBCs) from analysed fields allows an RCM to be constrained to follow the observed large-scale atmospheric evolution, while still permitting local interactions between parameterisations and the model's resolved dynamics. Furthermore, the spatial resolution of the model and therefore the scales classified as unresolved are well defined in an RCM. Careful design of an RCM grid can allow simulated variables to be confidentially evaluated against localised observations for a time-limited period, as is often the case with intensive observation campaigns. Comparisons can be then be made over a common thermodynamic phase space, with less chance that dynamical mismatches in space or time render the time-limited comparison meaningless.

RCMs have been extensively used in mid-latitude regions (Dickinson et al. 1989; Jones et al. 1995; McGregor 
1997; Christensen et al. 1997; Giorgi and Mearns 1999; Jones et al. 2004a) for regional climate change assessment, but have not been widely used specifically for improving parameterisation schemes. Relatively few RCMs have been applied to the Arctic (Rinke et al. 1997; Dethloff et al. 1996; Christensen and Kuhry 2000). The Arctic Regional Climate Model Intercomparison Project (ARCMIP, Curry and Lynch 2002; http://www.curry.eas.gatech.edu/ARCMIP) was developed to assess and document the performance of atmospheric RCMs over the Arctic. The first ARCMIP experiment was designed to capitalise on the SHEBA observation campaign (Uttal et al. 2002), occurring in the western Arctic between September 1997 and October 1998. The ARCMIP model domain was designed with the SHEBA observation camp at its centre (Fig. 1). The large amount of cloud and radiation observations taken at SHEBA offers the potential to evaluate RCM cloudradiation simulations over the Arctic and to utilise the observed data in further improving deficiencies identified in the RCM parameterisations.

This paper expands on two earlier articles analysing ARCMIP simulations (Tjernström et al. 2005; Rinke et al. 2006) by concentrating on cloud and radiation. Details of the specific set-up for the ARCMIP experiment can be found in these references, here we detail only the major points regarding the experiment design. All RCMs used a common set of lateral boundary conditions (LBC) derived from ECMWF (European Center for Medium-Range Weather Fore- casts) operational analyses. Sea ice concentrations were specified using 6-hourly SSM/I satellite data (Comiso 2002; http://www.nsidc.org/data/nsidc-0079.html), while prescribed Sea Surface Temperatures (SST) and sea-ice temperatures were derived from 6-hourly satellite observations, using the NOAA-AVHRR (Advanced Very High Resolution Radiometer) instrument (Key 2001). Snow accumulation and melting is computed by the RCMs, implying potential differences in the surface albedos between the various models.

In Sect. 2, the models and observation data sets are described. Model results and a comparison with observations are presented in Sect. 3. This evaluation is made at the monthly mean time scale (3.1), the daily time scale (3.2) and, for a limited period, using 3-hourly instantaneous values (3.3). Section 4 contains a discussion of the major findings and Sect. 5 conclusions and recommendations for future parameterisation development within the Arctic.

\section{Models and observation data sets}

\subsection{Overview of participating models}

The following eight RCMs participated in this study: RCA, REMO, HIRHAM, ARCSYM, PMM5, CRCM, COAMPS $^{\circledR}$ and RegCLIM. References for the models, along with details about the participating research groups, are listed in Table 1.
Fig. 1 Model domain of the ARCMIP experiment. The black box marked ARCMIP outlines the model domain used by RCA. All other RCMs used similar geographic domains and horizontal resolution $\left(0.5^{\circ}\right)$. Also shown is the location of the drifting SHEBA station

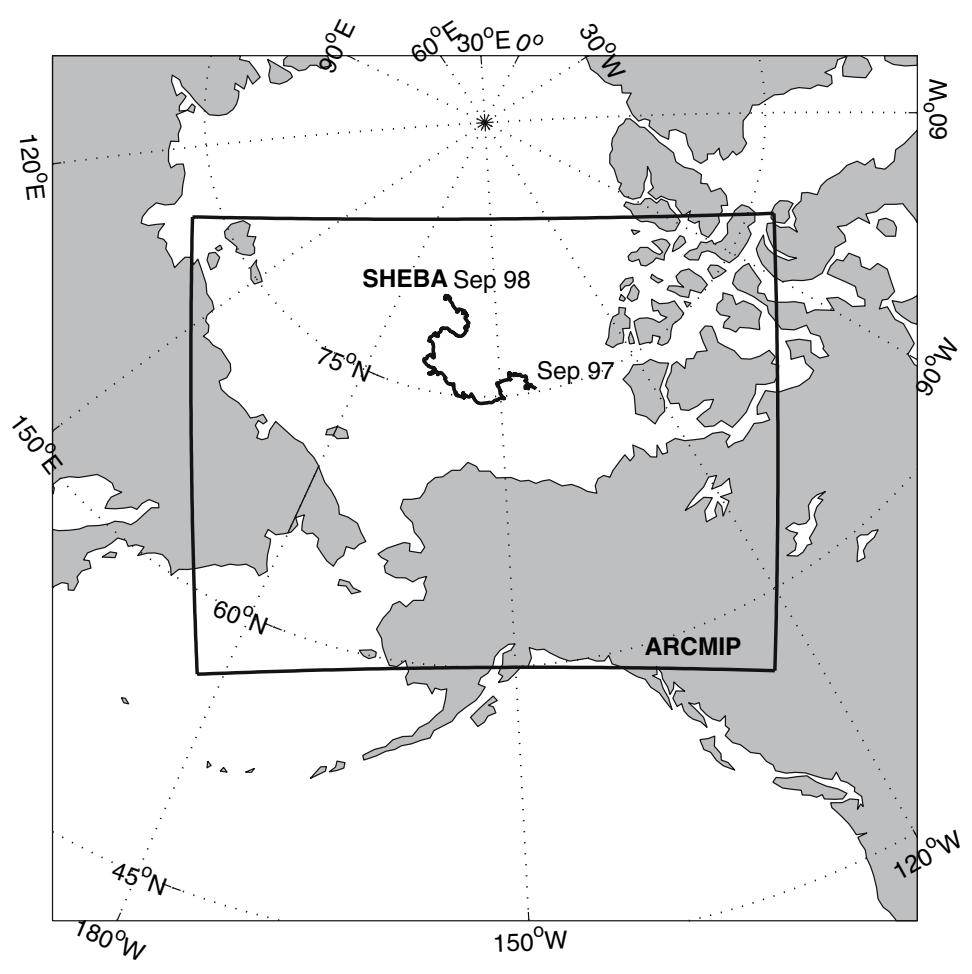


Each modeling group extracted cloud and radiation variables at the location of the SHEBA station, which drifted with the ice during the 13 month long campaign. Some of the modeling groups saved variables for the gridpoint collocated with the SHEBA station (RCA, ARCSYM, COAMPS ${ }^{\circledR}$, PMM5), while the other groups (HIRHAM, CRCM, RegCLIM, REMO) interpolated their model data to the ship's location. Each group reported daily means for 13 months, and 3-hourly (6-hourly from RegCLIM) instantaneous values from April to September 1998. Based on the daily means we computed monthly means for the SHEBA year, coincident with the evolving position of the SHEBA station.

The variables we choose to analyse are: total cloud cover, vertically integrated water vapour (IWV), downward longwave radiation (LWD) at the surface, downward shortwave radiation (SWD) at the surface, liquid water path (LWP) and surface albedo. These variables constitute the main components and controls on the surface radiation budget over the Arctic. We recognize the need to also include ice-water path in our analysis, unfortunately accurate observations of this variable were not available over SHEBA at the time of analyzing these model integrations. The microwave radiometer used to measure IWV and LWP (see Sect. 2.2) cannot operate during periods of precipitation. To reduce the risk of a potential bias, where necessary we filtered the model values accordingly. IWV and LWP were removed from each model dataset if the model in question produced more than $0.2 \mathrm{~mm}$ of precipitation over the $3 \mathrm{~h}$ period directly preceding the time point in question.

\subsection{Observation data sets}

For comparison between model results and observations, we mainly use the integrated SHEBA data set, (http:// www.atmos.washington.edu/ roode/SHEBA.html), prepared by de Roode. This data set contains hourly averaged observations from surface radiometers (Persson et al. 2002) and the microwave radiometer operated at SHEBA (Liljegren 1999). These platforms provide observations of surface SWD and LWD along with LWP and IWV.

Cloud base height and temperature were obtained from the NOAA-ETL (Environmental Technology Laboratory) combined lidar/radar data set (http://www.joss.ucar.edu/ sheba/index.html), which combines ETL lidar and radar data with atmospheric profiles from radiosondes (Intrieri et al. 2002a). The ETL data has a 10 min time resolution. Here we use the so-called best estimate for cloud base height, which is the height of the lowest cloud base measured with the lidar when available and otherwise with the radar. Cloud base temperature was inferred from the observed cloud base height and the temperature profile from the closest radiosonde.

The AVHRR Polar Pathfinder (APP, Fowler et al. 2000) data set is used for validation of cloud cover and surface albedo at the monthly timescale. This data has been derived from a set of twice daily composite satellite images, regridded to an equal area grid at $5 \mathrm{~km}$ resolution. Each pixel of an image is classified as cloudy or clear with the help of a multi-day algorithm that uses statistical properties of the observed radiances during a number of days to refine cloud detection (Key 2002). Cloud cover is defined as the fraction of cloudy pixels in an $11 \times 11$ array centered on the SHEBA location

A potential problem in the cloud cover comparison is the use of satellite images that are available only twice daily, computing a daily average or deriving instantaneous 3-hourly data will clearly be accompanied by a large uncertainty. Therefore, we also derived a cloud cover estimate from the ETL lidar/radar cloud observations in
Table 1 Participating models and institutions

\begin{tabular}{|c|c|c|c|c|}
\hline Model & Institution & Model reference & $\begin{array}{l}\text { Number of } \\
\text { vertical levels }\end{array}$ & $\begin{array}{l}\text { Timestep } \\
(\min )\end{array}$ \\
\hline RCA & $\begin{array}{l}\text { Swedish Meteorological } \\
\text { and Hydrological Institute }\end{array}$ & Jones et al. $(2004 a, b)$ & 24 & 30 \\
\hline REMO & $\begin{array}{l}\text { Max Planck Institute for } \\
\text { Meteorology }\end{array}$ & Jacob (2001) & 20 & 5 \\
\hline HIRHAM & Alfred Wegener Institute & $\begin{array}{l}\text { Christensen et al. (1996), } \\
\text { Dethloff et al. (1996) }\end{array}$ & 19 & 5 \\
\hline ARCSYM & University of Colorado & Lynch et al. $(1995,2001)$ & 23 & 2.5 \\
\hline PMM5 & University of Colorado & $\begin{array}{l}\text { Bromwich et al. (2001), } \\
\text { Cassano et al. (2001) }\end{array}$ & 23 & 2.5 \\
\hline COAMPS $^{\circledR}$ & Stockholm University & Hodur (1997) & 30 & 1.5 \\
\hline CRCM & $\begin{array}{l}\text { University of Quebec } \\
\text { à Montreal }\end{array}$ & $\begin{array}{l}\text { Laprise et al. (1998); } \\
\text { Caya and Laprise (1999) }\end{array}$ & & \\
\hline RegCLIM & Met.no, Oslo & Christensen et al. (1996) & 19 & 3 \\
\hline
\end{tabular}


place of the satellite cloud cover for the comparison at shorter timescales (daily mean and 3-hourly instantaneous comparisons in Sects. 3.2 and 3.3). A cloud presence flag is set depending on whether the ETL instruments register a cloud at a given time. This cloud presence flag is then timeaveraged to yield an estimate of the cloud cover. It should be noted that this estimate is not exactly compatible with the model's definition of cloud cover that is based on the sub-grid scale fractional area of a model column that is filled with clouds. The lidar and radar instruments detect clouds in a narrow overhead sector with high temporal resolution. The lidar/radar and the satellite derived cloud cover agree during summer, but in winter the lidar derived cloud cover is higher because of its increased ability to sense optically thin clouds (Wyser and Jones 2005).

For daily mean comparisons, all available observations from a 24-h period are included, while for the instantaneous 3-hourly comparison, we take the closest observation in time, but only if the time difference between the models and observations is less than $30 \mathrm{~min}$. The 10 -min values of the ETL data set are averaged over $1 \mathrm{~h}$ intervals centered on the 3-hourly model output times.

\section{Results}

\subsection{Time series of monthly averages}

This section gives an overview of the RCMs performance during the SHEBA year at the monthly mean time scale. Some model deficiencies are identified. A more detailed analysis using daily averages and 3-hourly instantaneous values follows and is used to better understand the simulations of cloud-radiation in the respective models and clarify some of the underlying causes of the biases identified in this section.

\subsubsection{Radiation}

The average of all models gives a reasonable estimate for the annual cycles of surface SWD and LWD at the SHEBA site (Fig. 2). There are, however, large variations between the models as well as between any individual model and the observed monthly mean. Removing the models with the largest difference to the observations, we find the SWD monthly means are simulated to within $30 \mathrm{~W} / \mathrm{m}^{2}$ and the
Fig. 2 Monthly mean surface SWD and LWD radiation, surface albedo, cloud cover, and vertically integrated water vapour. OBS denotes observations from (i) the radiometers at the SHEBA site (SW and LW), (ii) line-albedo, (iii) APP satellite cloud cover, and (iv) MWR vertically integrated water vapour
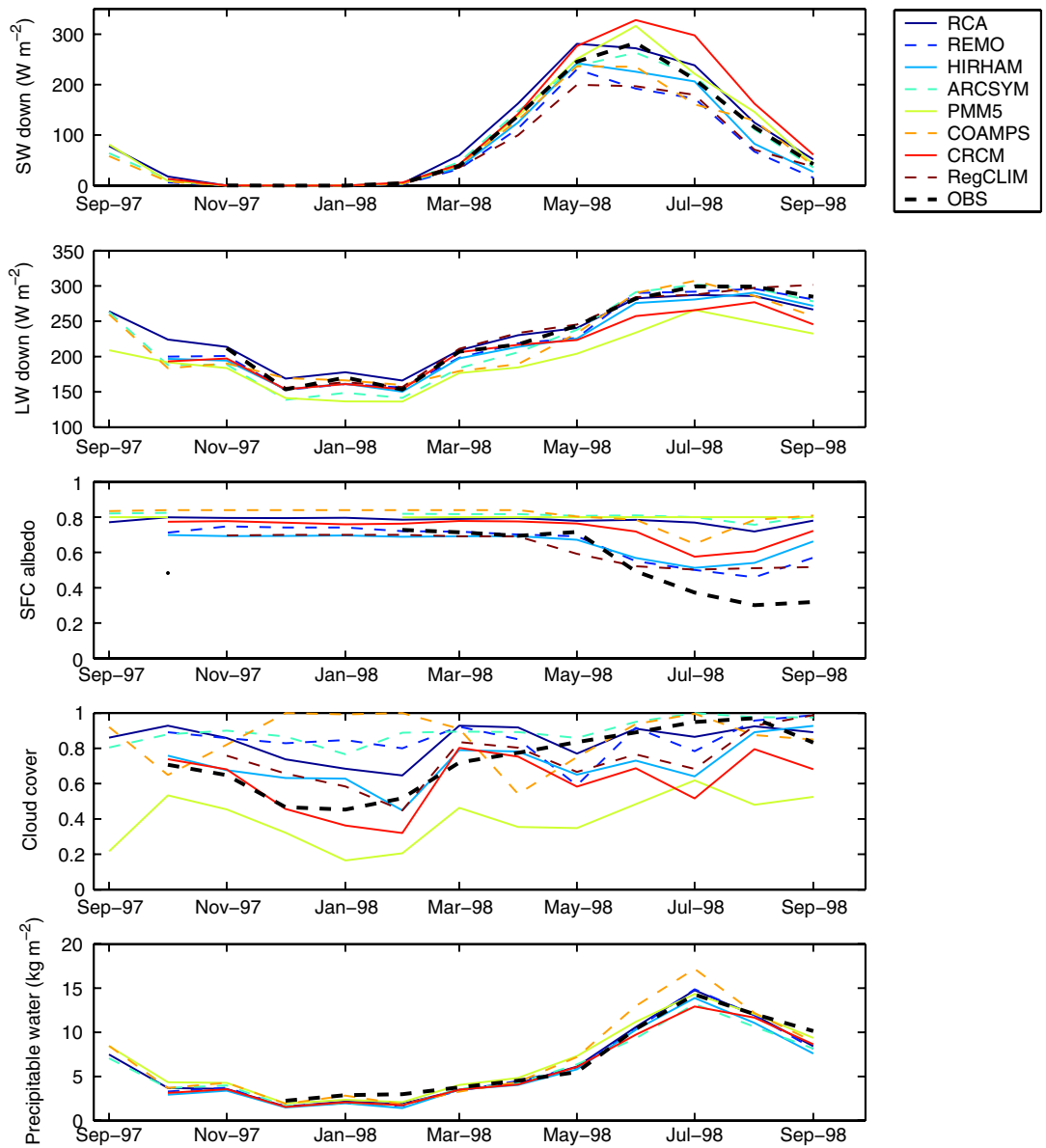
LWD monthly means to within $20 \mathrm{~W} / \mathrm{m}^{2}$. These differences are comparable to the difference between NCARNCEP and ERA40 reanalysis for the Arctic that differ by $38 \mathrm{~W} / \mathrm{m}^{2}$ (SW) and $20 \mathrm{~W} / \mathrm{m}^{2}$ (LW) in the annual mean (Sorteberg et al. 2007).

For SWD the largest spread between the RCMs occurs in June, when insolation is highest. The difference between the lowest and the highest model value exceeds $100 \mathrm{~W} \mathrm{~m}^{-2}$ in this month. Peak solar radiation is observed in June, but five models (RCA, RegCLIM, REMO, COAMPS ${ }^{\circledR}$ and HIRHAM) simulate maximum SWD in May. This temporal offset occurs at the onset of the snow/ice melt season and in a coupled Arctic ocean-atmosphere-ice model would lead to an early melting of snow and sea-ice. Surface albedo feedbacks would subsequently cause a further increase in the net SWD absorbed at the surface and a continued melting of sea-ice, leading to a serious bias. In the ARCMIP experiment, this was not a critical issue due to the prescribed lower boundary condition. The May maximum in SWD coincides with a relative minimum in simulated cloud cover in a number of RCMs.

While the inter-model differences in surface LWD are smaller than for SWD, the spread across models is still large. Most outstanding is PMM5, which has LWD values systematically lower than observed for the entire year. CRCM LWD is also biased low $\left(30-40 \mathrm{Wm}^{-2}\right)$ from May to September. LWD underestimates in both of these models appear directly related to negative biases in simulated cloud cover. LWD in COAMPS ${ }^{\circledR}$ is close to the observed value in winter and summer, but substantially lower in fall and spring. A significant LWD deficit in spring may also delay sea-ice melt in a coupled Arctic ocean-atmosphereice model, with a subsequent amplification of this error through surface albedo feedbacks.

\subsubsection{Cloud cover}

The satellite derived cloud cover at SHEBA shows a distinct annual cycle, with a minimum of $\sim 50 \%$ in winter and a summer season maximum approaching $95 \%$ coverage. Many of the participating RCMs have difficulty reproducing this annual cycle, especially the winter minimum. This could be a real problem with the simulations, but it may also be related to difficulties with the observation of clouds in the Arctic winter. Wyser and Jones (2005) have shown that cloud observations from different instruments at the SHEBA site disagree during winter by as much as $50 \%$, most likely due to different sensitivities of the respective instruments to detect optically thin clouds. Models count even the smallest amount of cloud water/ice as a cloud, regardless of its optical thickness, simulated cloud cover is thus likely to be on the high side compared to observations.

It is worth noting that the inter-model spread and bias of simulated LWD is small during winter despite a very large spread in the simulated winter cloud cover, implying that many of the simulated clouds, attributed as erroneous with respect to the AVHRR values (a positive model bias), are optically very thin and, as a result, do not greatly influence surface LWD. Wyser and Jones (2005) suggest a threshold that should be applied to modeled cloud amounts when they are compared to observed values. This threshold would ideally be based on a known optical thickness limit, below which a given instrument fails to 'see' an optically thin cloud. Simulated clouds with optical thicknesses below this threshold should then be removed from the model dataset before being compared to the observed cloud dataset in question. With respect to NOAA-AVHRR cloud cover over Scandinavia, Karlsson et al. (2006) suggest a lower cloud detection limit in the optical thickness range $0.5-2.5$, with a median value of $\sim 1.0$. In the simulations reported in Wyser and Jones (2005), using the RCA model, removing all clouds with an optical thickness below 1.0 reduces the simulated winter cloud cover at SHEBA in their model by $\sim 40 \%$ (see their Fig. 3). While this result may be model dependent, it suggests the cloud cover errors presented in Fig. 2 should be viewed with some caution, particularly in the winter season.

Cloud cover varies widely between the different RCMs throughout the year. None of the models except PMM5 is systematically biased with respect to the observations. PMM5 underestimates cloud cover throughout the year, which has consequences for the simulated surface radiation, namely too much surface SWD and too little LWD compared to observations. Cloud cover in the other models stays relatively close to the observations outside of the winter season, although CRCM, HIRHAM and RegCLIM do underestimate cloud cover in the spring and summer. The cloud cover underestimate in CRCM is clearly correlated with a negative bias in LWD in that model, consistent with an excess fraction of the total LWD emanating from higher altitudes under clear-sky conditions. To a lesser extent the cloud cover underestimates in HIRHAM and RegCLIM are also associated with a negative bias in LWD. CRCM simulated SWD also shows a positive bias in spring and summer, consistent with an underestimate of cloud cover. RegCLIM and HIRHAM, on the other hand, both significantly underestimate SWD in spring and summer $\left(-80 \mathrm{Wm}^{-2}\right.$ in RegClim and $-60 \mathrm{Wm}^{-2}$ in HIRHAM in June) even with a negative bias in cloud cover, suggesting that when clouds are present in these models, their cloud-albedo is considerably too high (this point will be returned to in Sect. 3.3.2). 
Fig. 3 Observed versus modelled SWD downwelling surface radiation (in $\mathrm{W} \mathrm{m}^{-2}$ ), using daily average values. Observations are plotted along the $x$-axis and model results along the $y$-axis. Below each plot we list the linear correlation coefficient $(r)$, the bias, and the root mean square error $(R M S E)$ of the model result and the observation timeseries. The number of days $(n)$ with valid observations and model results is also shown
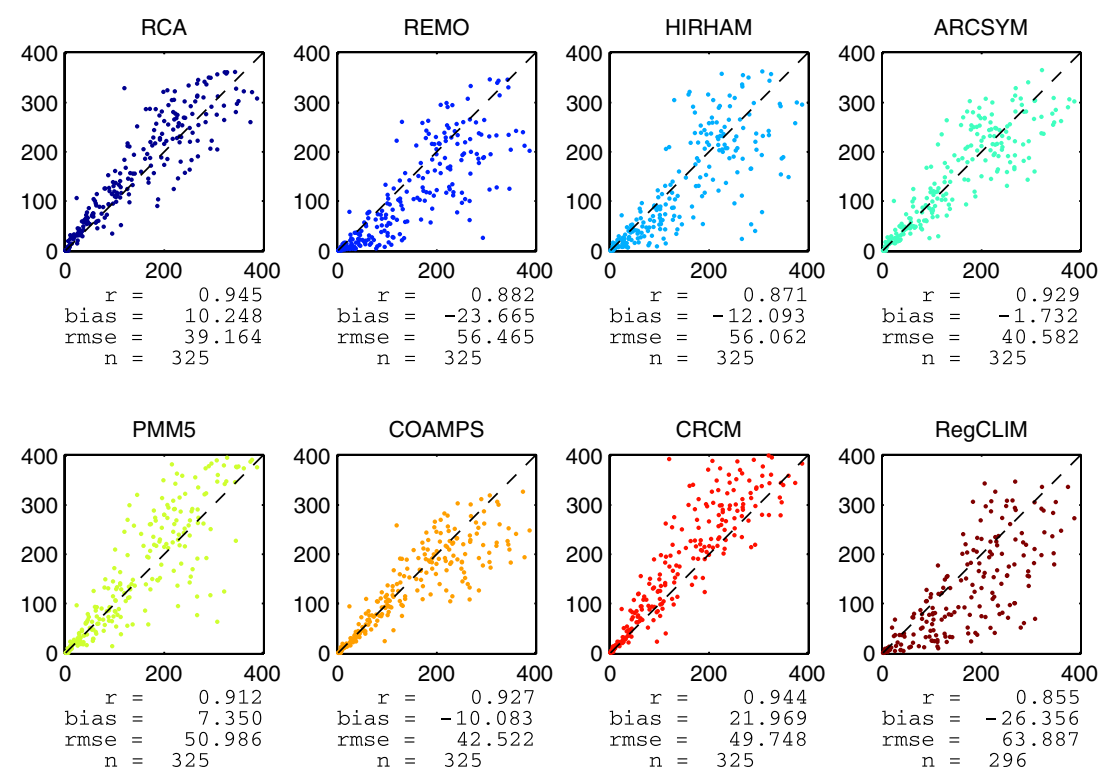

\subsubsection{Surface albedo}

The surface albedo is high in winter and early spring until the snow lying on sea-ice begins to melt, exposing patches of darker snow-free sea-ice and thereby lowering the areaaveraged albedo (Fig. 2). During summer, melt ponds on the sea-ice surface further lower the area-averaged albedo towards values as low as 0.35 (Curry et al. 2001; Perovich et al. 2002). In winter five of the models (RCA, ARCSYM, PMM5, COAMPS ${ }^{\circledR}$ and CRCM) have albedos of 0.8 or above, while REMO, HIRHAM, and RegCLIM lie between 0.7 and 0.75 . During summer, the albedos of the different RCMs are split in two distinct groups: RCA, ARCSYM, PMM5 and COAMPS ${ }^{\circledR}$ show no or only a marginal decrease in albedo from their winter values, while the other models reproduce, to some extent, the seasonal decrease in surface albedo. The albedo in PMM5 is specified as a fixed value and does not vary from summer to winter.

The albedo of a model is an area average representative for an area measuring $50 \times 50 \mathrm{~km}^{2}$ which generally includes varying portions of open water and sea-ice covered by snow, meltponds or exposed sea-ice. Most RCMs employ a parameterization to represent the time evolution of the sea-ice albedo, with schemes varying in complexity. Simpler schemes link the albedo to the surface temperature, with a linear decrease from a maximum albedo at cold temperatures to a minimum value at the melting point (Pedersen and Winther 2005). More advanced schemes use a semi-prognostic approach to the snow-albedo, whereby the history of the snow and snowfall events influence the subsequent evolution of the snow albedo. These schemes attempt to factor in the aging of lying snow which causes a gradual reduction in snow-albedo, as well as the occurrence of a new snowfall which rapidly increases snow-albedo back to values typical for new snow (e.g. Verseghy 1991; Douville et al. 1995).

The four models that largely fail to simulate a reduction of surface albedo in the summer (RCA, ARCSYM, PMM5 and COAMPS ${ }^{\circledR}$ ) all have albedos that are systematically too high in the winter season. This may be due to a poor basic specification of the snow albedo in these models, or that the impact of snow aging on albedo is too weak, or finally that these models precipitate snow too frequently, causing an aging snow-albedo to be repeatedly set back to a value representative of new snow. It is beyond the scope of this study to determine the specific causes of the overestimated albedo in these models. Nevertheless, it appears that a feedback occurs in these models whereby too high snow-albedo in the winter leads to an underestimate of solar radiation absorbed at the snow surface in early spring. This underestimate slows or even prohibits the melting of snow in these models, thereby keeping their surface albedo unrealistically high throughout the summer season. It is conceivable that if the snow albedo in a given model is too high, then sea-ice may remain snow covered throughout the summer season. Snow generally has a higher albedo than exposed sea-ice (0.7-0.9 for snow compared to $0.4-0.6$ for sea-ice (Perovich 1998). An erroneous presence of snow on sea-ice will therefore severely reduce the overall sea-ice melt during the summer. In a coupled Arctic ocean-atmosphere-ice model this type of error would lead to a significant overestimate of sea-ice distribution and thickness. Systematic errors of this type would also compromise the reliability of simulated snow/sea-ice albedo feedbacks in response to increasing levels of greenhouse gases within these models. 
The second group of models (HIRHAM, RegCLIM and REMO) that do simulate a reduction of surface albedo during the summer, all have lower albedo values in the winter season allowing for increased solar absorption in early spring, more rapid snow melt and exposure of sea-ice during the summer. CRCM has an intermediate value of surface albedo in the winter and lies between these two groups with respect to a reduction of albedo in the summer. A correct representation of the winter season albedo appears a prerequisite for simulating spring snowmelt and the subsequent evolution of surface albedo.

The two groups of models, classified by their summer albedos, also seem to group to a large extent with respect to simulated surface SWD (see top panel in Fig. 2). HIRHAM, REMO and RegCLIM all underestimate incoming solar radiation at the surface in the spring and summer, while RCA, ARCSYM and PMM5 all have relatively accurate estimates of SWD. While cloud errors clearly dominate SWD errors in some models (e.g. CRCM and to a lesser extent PMM5), it is interesting that models with excessive surface albedo systematically have higher SWD in the spring and summer than models with lower (more correct) surface albedos.

The Arctic summer is characterized by large amounts of low-level clouds ( $95 \%$ in the observations in Fig. 2, also see Key and Barry 1990; Intrieri et al. 2002a) and a relatively high surface albedo. In this situation a significant fraction of the downwelling solar radiation will be reflected from the sea-ice/snow surface and subsequently be reflected back down to the surface from cloud-base. It is important that models accurately include these multiple reflections in their calculation of the total incoming solar radiation. Tests made with the parameterization of multiple reflections in the RCA model indicate the total downwelling surface solar radiation is extremely sensitive to a correct inclusion of this term. If most models underestimate the contribution of multiple reflections to the total downwelling solar radiation, then they may require a positive bias in surface albedo (excess reflection of SWD from the surface) to compensate for this underestimate. They therefore achieve an accurate simulation of the total downwelling solar radiation through two compensating errors, excess surface reflection of SWD and an underestimate of the reflection of this radiation, from cloud-base back to the surface. In contrast, a correct (reduced) amount of surface reflection, coupled with an underestimate of cloud base downward reflection, will lead to an underestimate in the total incoming SWD. This reasoning is consistent with the SWD and surface albedo results presented in Fig. 2, but more detailed analysis by the individual modeling groups would be required to substantiate this theory. Suffice to say, we highlight multiple reflections of solar radiation between the snow/sea-ice surface and cloud- base as an important term requiring careful treatment in radiation schemes applied over the Arctic.

\subsubsection{Water vapour}

The observed vertically integrated water vapour (IWV) reflects the annual cycle of temperature: low in winter and high in summer. Most models reproduce the observed annual cycle quite well, mainly thanks to the prescribed SST and sea ice cover that effectively constrains conditions near the surface, where most of the water vapour is found. Lateral boundary conditions for the RCMs are also identical, so that long range water vapour transport from low latitudes is the same in all models, contributing to the small inter-model spread in IWV. During winter there is a systematic negative bias between the RCMs and the observed IWV. This bias may arise from too low prescribed surface temperatures in all the models. Tjernström et al. (2005) contend that there is a systematic difference between the ice-surface temperatures derived from satellite at the SHEBA site (and used in the simulations) and in-situ observations during cold conditions.

COAMPS $^{\circledR}$ is the only model to deviate significantly from observed IWV values outside of the winter season, with too high values in June and July leading to low clearsky solar transmissivity. This may partially explain the lower than observed SWD in this model.

\subsection{Comparison of daily averages}

In this section we compare diurnally averaged model results against observed values and present the result as scatterplots. Observations are always plotted along the $x$-axis and model results along the $y$-axis, a 1:1 line has been added to the plots that would indicate a perfect agreement between models and observations. Below each figure are listed the linear correlation coefficient between the model results and observations at the daily time scale, the model bias, the root mean square error (RMSE), and the number of days included in the comparison. This number varies because observational datasets contain missing data and because the length of the time series differs slightly between the models. Only days with both valid model results and observations have been included in the statistics.

\subsubsection{Radiation}

All RCMs reproduce the observed SW radiation quite well; the correlation coefficient being relatively high for all models (Fig. 3). ARCSYM has a small bias, which is also reflected in the symmetry of its SWD scatterplot. RegCLIM, REMO, HIRHAM and COAMPS ${ }^{\circledR}$ all have negative biases while RCA, CRCM and PMM5 tend to overestimate 
the surface SWD. For most models, the scatter increases towards larger values, suggesting a proportionality between the error and the magnitude of the absolute value. REMO, HIRHAM and RegCLIM all have negative biases in surface SWD while also underestimating cloud cover in the summer season. Of the three models exhibiting a positive SWD bias, PMM5 has the smallest bias. This is somewhat surprising given the severe underestimate of cloud cover in PMM5 (Fig. 2). Subsequent analysis will show that the decrease in surface SWD as a function of increasing cloud water is far too rapid in REMO, HIRHAM, RegCLIM and PMM5 (Fig. 8), leading to clouds being excessively reflective when they are present in these four models, helping to explain the apparent contradictory biases with respect to surface SWD and cloud cover. We defer a discussion of the cause of this problem until Sect. 3.3.2 where we present relationships between SWD and LWP for both the models and observations.

COAMPS $^{\circledR}$ also shows a negative bias in surface SWD while having a reasonable simulation of cloud amounts, at least in the spring and summer seasons. The cause of the negative bias in surface SWD in COAMPS ${ }^{\circledR}$ seems more related to an overestimate of IWV (Fig. 2) leading to a clear-sky atmosphere that is too opaque.

CRCM systematically overestimates SWD, consistent with an underestimate of cloud cover (Fig. 2), while RCA has a positive bias in SWD concurrent with a reasonable simulation of the annual cycle of cloud cover. Later analysis will indicate the RCA surface SWD in clear-sky conditions is overestimated (Fig. 11). In particular, at large solar zenith angles $\left(>65^{\circ}\right)$ the sensitivity of RCA clear-sky solar transmissivity to increasing amounts of integrated water vapour is underestimated, with too much solar radiation reaching the surface in clear-sky, moist conditions. Unlike COAMPS ${ }^{\circledR}$, this clear-sky SW transmission error is not directly due to an overestimate of IWV, rather to the actual treatment of water vapour in the RCA solar radiation scheme. This error was quantified in Jones et al. (2004b) for stand-alone radiation tests in clear Arctic atmospheres to be of the order $10-15 \mathrm{Wm}^{-2}$ positive bias. In Fig. 2, RCA has a positive bias in SWD in early spring (March to May); during this period the sun is low in the sky (large solar zenith angle) and excess clear-sky transmissivity at high solar zenith angle will directly contribute to the bias in the total surface SWD.

All models, except PMM5 and CRCM, reproduce the surface LWD fairly well and show high correlation coefficients (Fig. 4). The large negative biases in PMM5 $\left(-35 \mathrm{Wm}^{-2}\right)$ and CRCM $\left(-16 \mathrm{Wm}^{-2}\right)$ are consistent with the underestimate of cloud cover in these two models. The version of PMM5 used for the ARCMIP simulations used the CCM2 radiation parameterization (Hack et al. 1993, see also Table 2), which has a known negative bias in LWD (Pinto et al. 1999). Based on an analysis of the PMM5 ARCMIP simulations an updated versions of Polar MM5 now uses the RRTM radiation parameterization (Mlawer et al. 1997), which reduces the negative bias in LWD. The scatterplot for ARCSYM and to some extent also COAMPS ${ }^{\circledR}$ show two distinct clusters of points. This is a typical feature of models without fractional cloud cover (see Fig. 7 for an example of this in these two models), in which the radiation in any column is computed either for completely overcast or cloud-free conditions. The simulated surface LWD at a given gridpoint and timestep being either of two values: a low value when the gridpoint is clear, or a high value for overcast cases,
Fig. 4 As Fig. 3 but for LWD downwelling surface radiation (in $\mathrm{W} \mathrm{m}^{-2}$ )
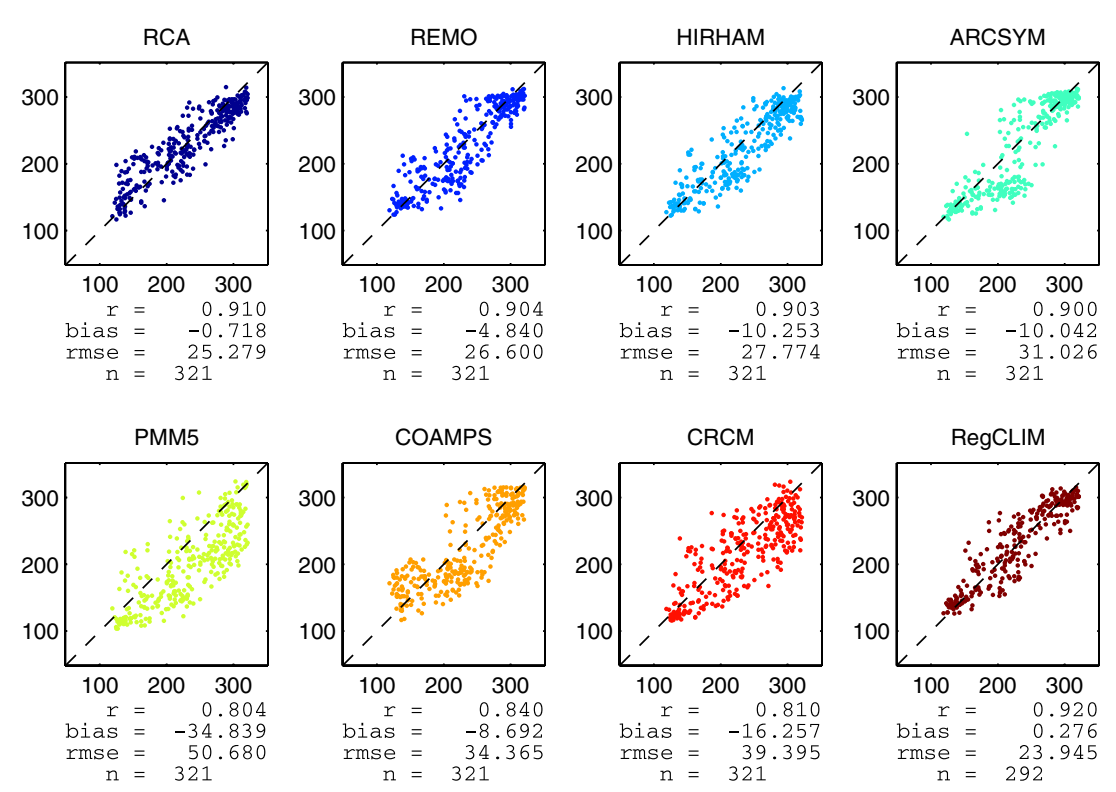
Table 2 Cloud and radiation schemes of the RCMs, and the range of effective radii (in $\mu \mathrm{m}$ ) for water and ice clouds, respectively

\begin{tabular}{lllll}
\hline Model & Cloud scheme & Radiation scheme & $r_{\mathrm{e}}$ water & $r_{\mathrm{e}}$ ice \\
\hline RCA & Rasch and Kristjansson (1998) & HIRLAM (Sass et al. 1994) & $4-24$ & $15-80$ \\
REMO & ECHAM4 (Roeckner et al. 1996) & ECHAM4 (Roeckner et al. 1996) & $4-24$ & $12-80$ \\
HIRHAM & ECHAM4 (Roeckner et al. 1996) & ECHAM4 (Roeckner et al. 1996) & $4-24$ & $12-80$ \\
ARCSYM & Hsie et al. (1984) & SW: CCM2 (Hack et al 1993) & 10 (SW) 7 (LW) & 40 \\
& & LW: RRTM (Mlawer et al. 1997) & & 10 \\
PMM5 & Reisner et al. (1998) & CCM2 (Hack et al. 1993) & 14.6 \\
COAMPS & Ruthledge and Hobbs (1983) & Harshvardhan et al. (1987) & $5-45$ & $10-60$ \\
CRCM & McFarlane et al. (1992) & SW: Fouqart and Bonnel (1980) & $\sim$ Liquid water content & $\sim$ Ice water content \\
& & LW: Morcrette (1984) & & 12-80 \\
RegCLIM & ECHAM4 (Roeckner et al. 1996) & ECHAM4 (Roeckner et al. 1996) & $4-24$ & \\
\hline
\end{tabular}

Observation estimates from Shupe et al. (2001) are 3-20 $\mu \mathrm{m}$ for liquid and 7-300 $\mu \mathrm{m}$ for ice clouds. Note that the observed value for ice clouds is for the mean diameter that may be larger than the effective radius

resulting in the separation of the data into an upper and a lower cluster.

RCA, REMO, COAMPS ${ }^{\circledR}$ and to a lesser extent HIRHAM all overestimate surface LWD when the observed values are very low $\left(<180 \mathrm{Wm}^{-2}\right)$. Such low values generally occur during extreme cold, cloud-free conditions in the Arctic winter. A number of studies (Niemelä et al. 2001; Wild et al. 2001) have shown that most radiation schemes actually underestimate clear-sky LWD during cold, clear-sky conditions, when compared to line-by-line codes or surface observations, rather than overestimating as seen in Fig. 4. Jones et al. (2004b) also show for 4 clearsky case studies over SHEBA that the RCA radiation scheme, when run in stand-alone mode using observed thermodynamic profiles, underestimates clear-sky LWD by $\sim 12 \mathrm{Wm}^{-2}$ while the more advanced RRTM (Rapid Radiative Transfer Model, Mlawer et al. 1997) has a smaller, yet still systematic underestimate of $\sim 5 \mathrm{Wm}^{-2}$ (see their Fig. 9a). While acknowledging the uncertainty in observed cloud amounts in winter, the positive winter cloud biases in Fig. 2, combined with the positive bias in surface LWD at low values of observed LWD (Fig. 4) and the earlier findings indicating a tendency for a negative bias in clearsky LWD in cold conditions, all suggest these models incorrectly simulate cloudy conditions during the extreme cold periods. The erroneous presence of clouds causes a positive bias in surface LWD during these periods, offsetting the probable negative bias in clear-sky surface LWD.

\subsubsection{Clouds}

Surface radiation agrees relatively well between models and observations with correlation coefficients exceeding 0.8 . However, such good agreement is no longer apparent when evaluating cloud cover. Comparing the simulated daily mean cloud cover against equivalent observations derived from the ETL combined lidar-radar dataset, we see that the correlation between observations and any of models is low. None of the models can accurately reproduce the observed cloud cover on a daily basis (Fig. 5). Clearly, it is an imperative to improve the representation of cloud cover in RCMs applied to the Arctic, if we are to have any confidence in simulated cloud-radiation-albedo feedbacks associated with increasing concentrations of greenhouse gases.

For LWP the correlation between models and observations is slightly improved compared to cloud cover (Fig. 6). The bias of all RCMs, except PMM5 and CRCM, is quite low, $\sim 10 \mathrm{gm}^{-2}$, which is comparable to, or less than, the microwave radiometer (MWR) uncertainty (Westwater et al. 2001), although it should be noted that observed LWP values at SHEBA rarely exceed $150 \mathrm{gm}^{-2}$. PMM5 not only has too few clouds, but when clouds are present they are predominantly composed of the ice-phase, leading to an underestimate of cloud liquid water and further exacerbating the cloud-radiation problems in this model. CRCM did not provide LWP in their diagnostic output, hence we were unable to plot any results for this model with respect to LWP.

\subsection{Co-variability of instantaneous values}

In order to better understand the physics of the different models we plot two model variables in relation to each other. The co-variation can then be compared against the co-variation of the corresponding variables from observations. For this comparison we make use of instantaneous 3hourly values that have been obtained for seven of the models. The dataset covers April-September 1998, which is the period when the sun rises sufficiently high above the horizon for meaningful comparisons of the SW radiation. 
Fig. 5 As Fig. 3 but for cloud cover
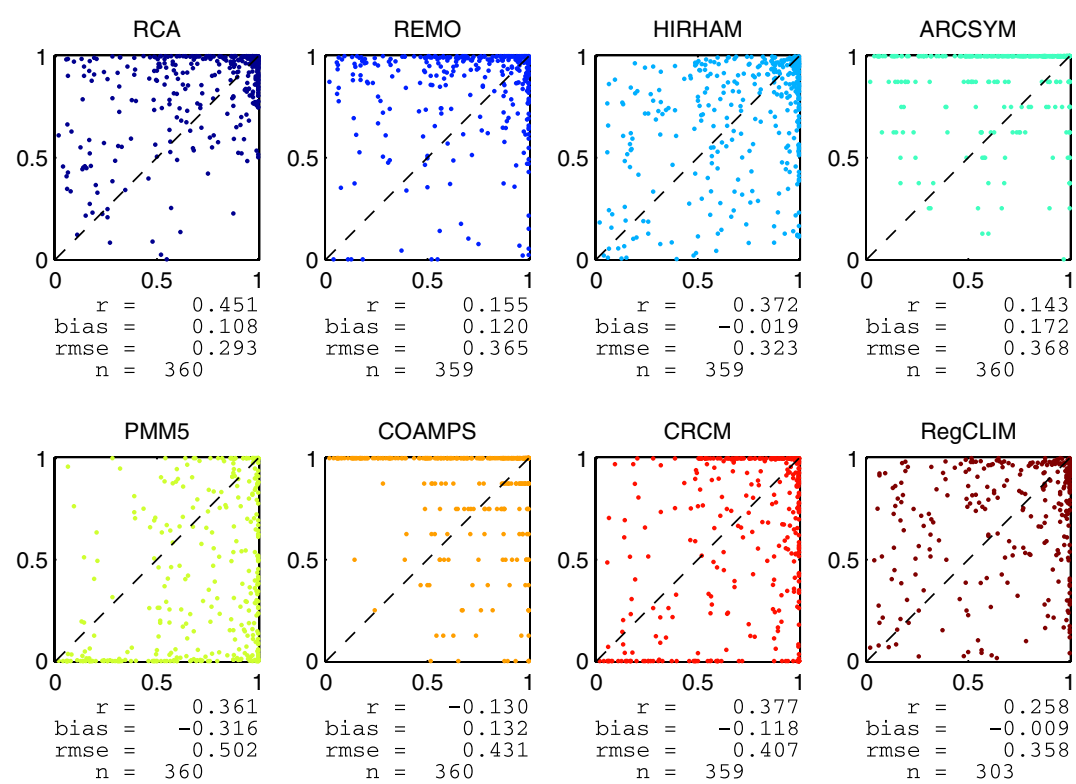

Fig. 6 As Fig. 3 but for vertically integrated cloud water path (in $\mathrm{kg} \mathrm{m}^{-2}$ )
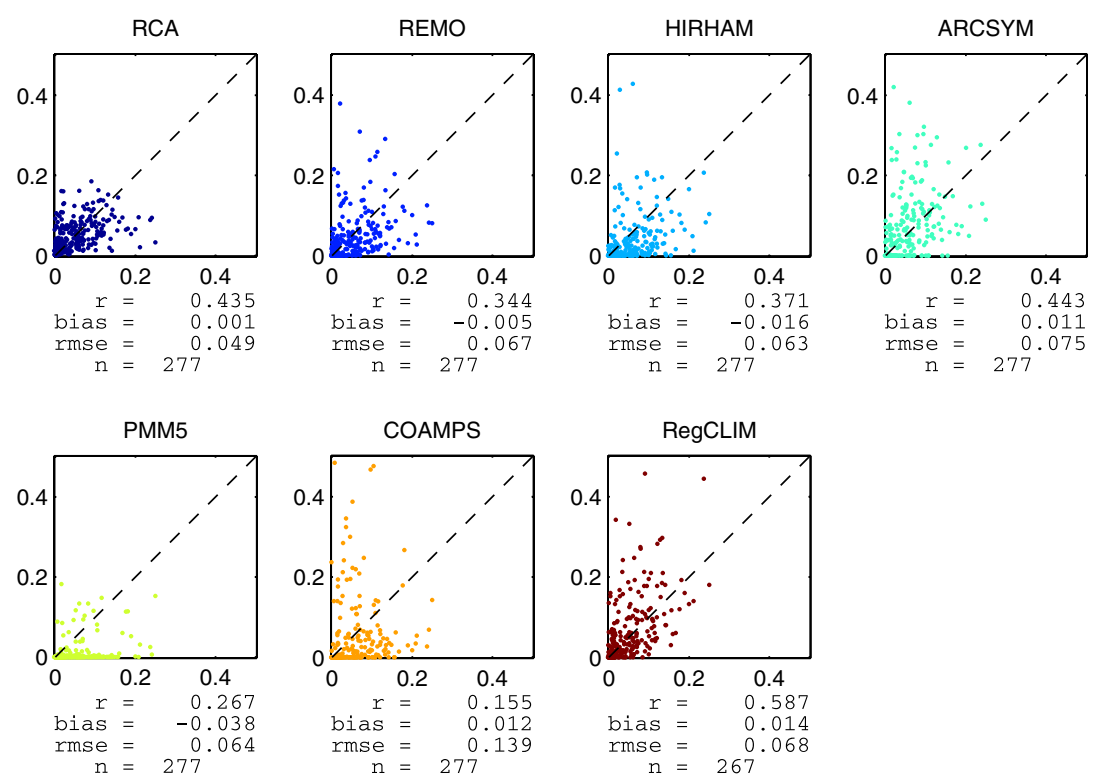

The drift of the SHEBA station with the sea-ice leads to a variation of the local solar angle with time that needs to be accounted for when investigating processes related to solar radiation. As a first order correction, we divide the surface SWD radiation with the cosine of the local solar zenith angle to account for the geometric increase in optical thickness with higher solar zenith angles. Physically speaking, this correction (commonly referred to as the airmass factor) gives an estimate of the surface radiation if the sun were continuously overhead. The same correction is applied to model results and observations. Unless stated otherwise, we also limit the dataset to those cases when the solar zenith angle is smaller than $65^{\circ}$, thereby removing the data when the sun is very low in the sky. At high solar zenith angles cloud sides become illuminated and in extreme cases even the cloud base. Most radiation schemes treat clouds as plane-parallel and of infinite extent (i.e. no sides), therefore, an evaluation of cloud-solar radiation interaction at high solar zenith angles does not seem justified.

The radiation at a single gridpoint in an RCM is a combination of contributions from clear sky and clouds. Comparing model values against observations is difficult since the fractional cloudiness is weighted into the radiation. To eliminate this possible source of uncertainty, where appropriate we filtered the datasets with respect to 
cloud cover. Cloud cover above 0.85 will be denoted as overcast, and cloud cover below 0.15 as clear-sky conditions. In these cases the data with cloud cover between 0.15 and 0.85 is discarded. For overcast skies we investigate the relationship between radiation and cloud water/cloud base temperature to see how well the RCMs capture the basic physics. For clear skies, we look at the relationship between radiation and vertically integrated water vapour. For fractional cloudiness we evaluate the change in surface SWD as a function of increasing cloud cover.

\subsubsection{Cloud cover and SWD radiation}

Surface SWD is expected to decrease with increasing cloud cover. From Fig. 7 the observations (grey +'s) hint this is the case, although the scatter is large and the signal not clear. One reason is that cloud detection with the lidar/ radar gives a binary response every $10 \mathrm{~min}$ that is then averaged over $1 \mathrm{~h}$ to get an area cloud cover estimate. The scatter in the observations could be mitigated if the cloud detection is weighted with the cloud optical thickness to get an effective cloud cover.

The scatter is smaller for the RCMs (coloured 's), and a decrease of the downward solar radiation with increasing cloud cover is apparent. Compared to the observations, the decrease seems not strong enough for CRCM and may be a symptom of this model lacking prognostic cloud liquid water. For REMO, HIRHAM and RegCLIM the decrease in surface SWD with increasing cloud cover is too strong. The too high sensitivity of these models to an increase in cloudiness is consistent with the excessive cloud albedo identified earlier. The impact of an incorrect cloud albedo will become more important the greater the fraction of a model grid box that is covered by cloud. Hence, the largest effect is found for overcast conditions.

ARCSYM and COAMPS ${ }^{\circledR}$ clearly have binary cloud cover in Fig. 7, with instantaneous values of 0 or 1 , consistent with the dual grouping of surface LWD see in Fig. 4. ARCSYM yields high values for surface SWD when the cloud cover is 0 as expected. In contrast this is not the case for COAMPS $^{\circledR}$ : the surface SWD for clearsky covers a similar range as when cloud cover is 1 , probably due to the excessive amounts of the water vapour in COAMPS $^{\circledR}$ seen in Fig. 2.

\subsubsection{Cloud water and SWD radiation}

Figure 8 shows the relationship between cloud water path and surface SWD for observations (grey +'s) and models (coloured.'s). Only values where the cloud fraction is greater than 0.85 in both models and observations are plotted. Cloud water path for the models includes contributions from both liquid and frozen condensate, while the MWR only measures liquid water. Thus, the observed cloud water in the graph is likely a slightly low estimate of the true, total cloud water (i.e. if ice were included the grey crosses, representing observations in Fig. 8, would move slightly to the right, along a horizontal with respect to observed SWD. The combined effects of ice and liquid water path variability are already accounted for in the observed SWD.)

All models show a more or less well-organized decrease of surface SWD with increasing cloud water. COAMPS ${ }^{\circledR}$ has many outliers with high surface SWD even when
Fig. 7 Variation of downwelling SWD radiation (in

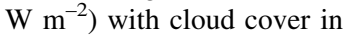
models (colored dots) and observations (grey crosses). Shown are only values for solar zenith angle below $65^{\circ}$
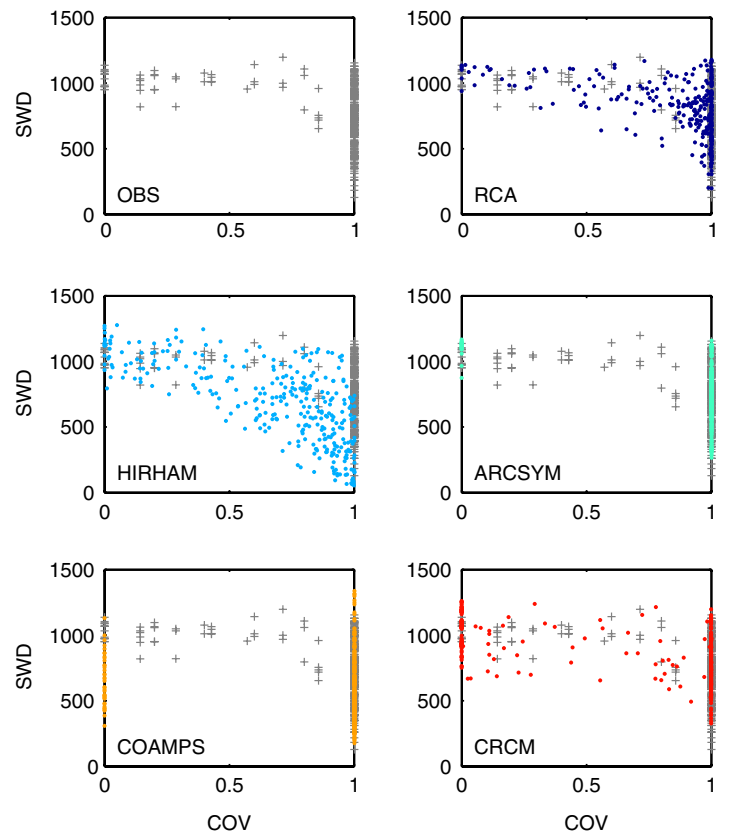
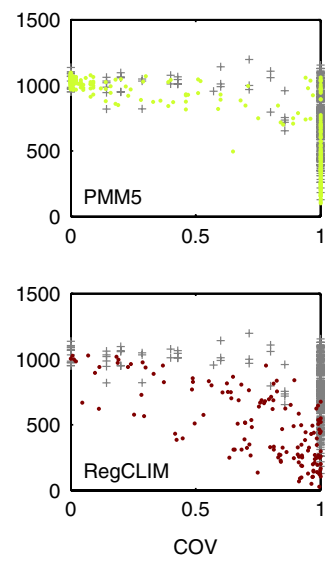
Fig. 8 Variation of downwelling SWD radiation (in

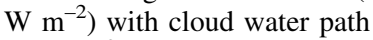
(in $\mathrm{g} \mathrm{m}^{-2}$ ) in models (colored dots) and observations (grey crosses). Shown are only values for overcast sky and solar zenith angle below $65^{\circ}$. The observed LWP values are for liquid water clouds, while the model data include contributions both from liquid and ice clouds water
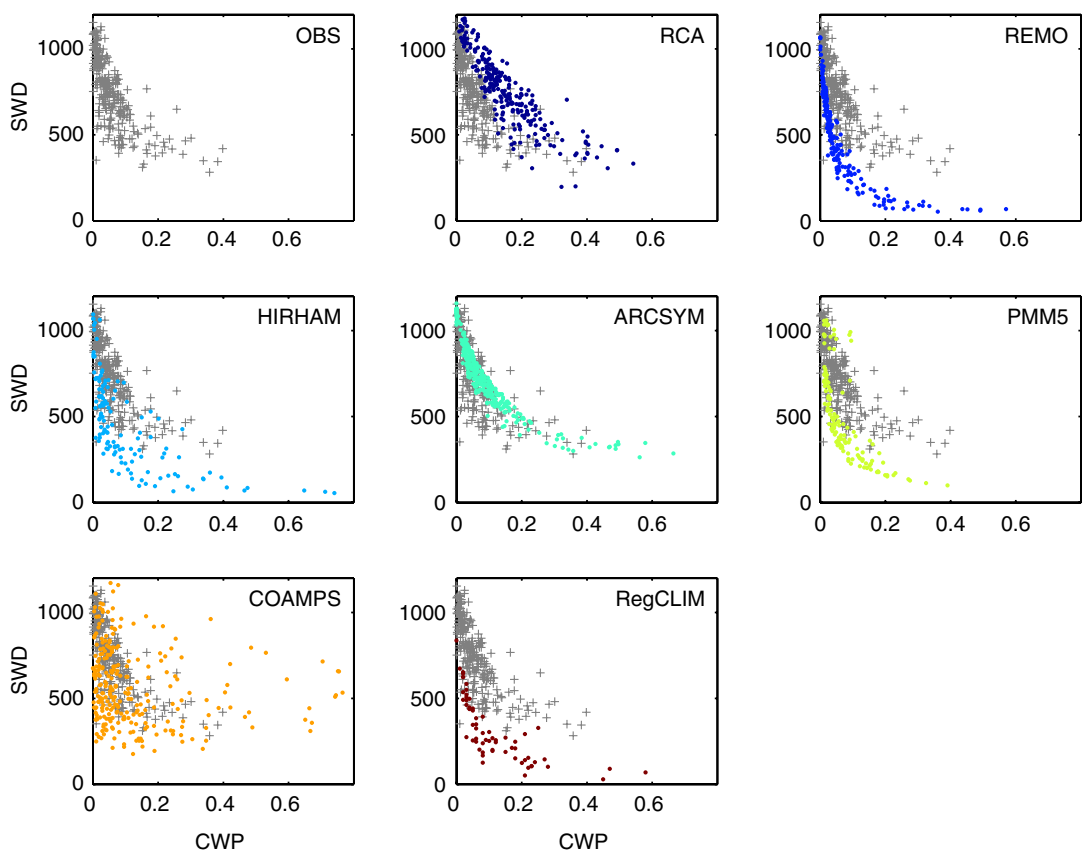

clouds are optically thick, suggesting a problem with the transmissivity of thick clouds in this model. Most models show a decrease of surface SWD with increasing cloud water path that is steeper than that seen in the observations. Keeping in mind that the plotted observed water path is a low estimate of the true value if ice were included, the difference between models and observations is likely to be even larger. In REMO, HIRHAM, PMM5 and RegCLIM, cloud transmissivity decreases too rapidly with increasing cloud water path. The parameterizations of cloud optical properties in these models were initially developed for mid-latitude conditions. In the Arctic conditions are different and appear to require a generalization of the cloud optical treatment. This type of behaviour can potentially arise from a number of sources, one being how models actually distribute prognosed cloud water between liquid droplets and ice crystals. For a given total cloud water amount, an overestimate of the liquid fraction will directly lead to an underestimate of the mean cloud effective radius and therefore an overestimate of cloud albedo (see Table 2 for the range of effective radii used in the ARCMIP models, expressed separately for liquid and solid phase). Reliable observational guidance on the fractional distribution of solid and liquid phase in Arctic mixed phase clouds is difficult to come by. Recent observations at SHEBA (e.g. Intrieri et al. 2002c; Shupe et al. 2006) do indicate that liquid is observed in Arctic clouds at temperatures as low as $-35^{\circ} \mathrm{C}$. The fractional amount of liquid versus ice water in these clouds appears to decrease linearly over the temperature range -10 to $-25^{\circ} \mathrm{C}$, although there is a large scatter in the observations (Shupe et al. 2006)
A second potential problem lies directly in the parameterization of effective radius for ice clouds. The observed mean diameter for ice clouds during the period April to July 1998 varies between 7 and $300 \mu \mathrm{m}$ (Shupe et al. 2001), while the mean effective diameter observed for mixed phase clouds over SHEBA was $93 \mu \mathrm{m}$, with a range of 27-200 $\mu \mathrm{m}$ (Shupe et al. 2006). The parameterizations of ice effective radius used in the ARCMIP RCMs generally have lower values than those observed at SHEBA (see Table 2), probably due to the fact they were developed based on observations from mid-latitude and tropical cirrus clouds (McFarquhar and Heymsfield 1998; Heymsfield and Miloshevich 2003). As a result, even with a correct total cloud water path and a correct separation of the cloud water into liquid and ice fractions, the radiation parameterizations will still yield a cloud albedo that is too high due to an underestimate of the median ice effective radius.

\subsubsection{Cloud base temperature and LWD radiation}

To investigate the relationship between cloud temperature and LWD radiation, we plot surface LWD as a function of the cloud base temperature (Fig. 9). The cloud base temperature is used as a proxy for the cloud temperature here, being well aware that the true cloud temperature could be different if the cloud base is optically thin in the thermal IR. To minimize the impact from clear-sky contributions, the graph only contains data for clouds with cloud cover larger than 0.85. Clouds with cloud base above $1,000 \mathrm{~m}$ have also been excluded to avoid the contribution of clear-sky emission, below high clouds, to the surface LWD. 
Fig. 9 Variation of downwelling LWD radiation (in

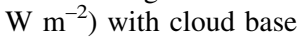
temperature (in K) in models (colored dots) and observations (grey crosses). Shown are only values for overcast sky with cloud base below $1,000 \mathrm{~m}$
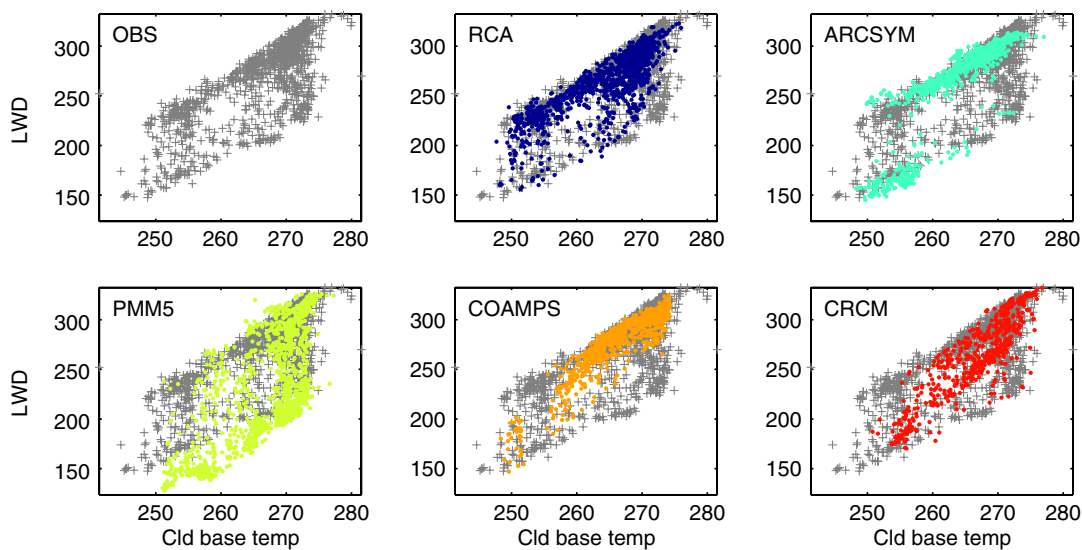

The emission of LW radiation follows the StefanBoltzmann law, with the emissivity $\varepsilon$ being a function of the amount of cloud water and humidity. When plotting surface LWD as a function of cloud base temperature, we find that the data points form a cloud that is bounded by an upper and a lower envelope (Fig. 9). The upper envelope is given by the emission from a blackbody $(\varepsilon=1)$, and the lower envelope by an emissivity that is smaller than 1 . For the observations, the lower bound is nicely fitted with $\varepsilon \sim 0.7$. An even better fit is obtained if the emissivity is not constant but the value for saturated air, with the saturation vapour pressure calculated from the cloud base temperature. We conclude that the radiative properties of the clouds over the SHEBA site are between that of saturated humid air and that of a blackbody. The majority of observed clouds are found close to the upper bound and therefore optically black, although there is still a significant number of clouds with emissivities in the range 0.7-1.

Not all models saved cloud base temperature, therefore the comparison includes only results from RCA, ARCSYM, PMM5, CRCM and COAMPS ${ }^{\circledR}$. All models capture the main physics with the LWD radiation between the two theoretical limits of saturated humid air and a blackbody. However, there are clear differences between the models. In RCA almost all clouds are blackbodies, with very few cases where the emissivity is substantially smaller than 1 . In ARCSYM, CRCM and COAMPS ${ }^{\circledR}$, clouds are mostly blackbodies as long as the temperature is above $260 \mathrm{~K}$. Below $260 \mathrm{~K}$, the emissivity of clouds drops to that of humid air in these models, suggesting the emissivity of cold clouds is too low. Possibly there is a problem with the water content of cold clouds, not containing enough liquid water or ice. An alternative explanation is that there is a more general problem with the calculated emissivity of ice clouds. At low temperatures, ice clouds grow in importance relative to water clouds. Too small emissivity of ice clouds at cold temperatures would imply an underestimate of surface LWD, as seen in Fig. 9.
PMM5 surface LWD shows good agreement with observations, but only for temperatures below $270 \mathrm{~K}$. At higher temperatures, the surface LWD of the model can often be significantly lower than the corresponding observations. The sharp transition of regimes at $\sim 270 \mathrm{~K}$ suggests a problem with liquid and not ice clouds in PMM5. The emissivity of water clouds in PMM5 can even be lower than that of saturated, humid clear air. The most likely cause of this error is that PMM5 cloud water amounts are too low. This is supported by Fig. 6, where observed LWP is plotted against the simulated value. PMM5 LWP is consistently lower than observed values, with a large mean negative bias.

\subsubsection{Clear-sky SW transmission and integrated water vapour}

Under clear-sky conditions, solar transmissivity varies primarily as a function of the amount of water vapour in the air (note that the strong dependency on the solar zenith angle has been removed by applying the airmass correction). Plotting surface clear-sky SWD as a function of the vertically integrated water vapour, for the observations at SHEBA, shows a gradual decrease in surface SWD with increasing amounts of water vapour (Fig. 10).

We now separate the data according to solar zenith angle to remove some of the scatter in the graph. For data with solar zenith angle $<65^{\circ}$ (Fig. 10), most models agree fairly well with the observations. In $\operatorname{COAMPS}^{\circledR}$, the transmissivity of the atmosphere is too sensitive to water vapour. Another noteworthy feature is the large scatter found for HIRHAM, CRCM and COAMPS ${ }^{\circledR}$. The reason for this scatter in the surface SWD, in conjunction with the variation of the water vapour, is not clear. In HIRHAM there is a strong variation of the surface albedo at snow melt (Fig. 2) which could be responsible for the scatter in this model, as some data will be for conditions with snow on the ground, and others for bare surfaces. The water 
Fig. 10 Variation of downwelling SWD radiation (in $\mathrm{W} \mathrm{m}^{-2}$ ) with vertically integrated water vapour (in $\mathrm{kg} \mathrm{m}^{-2}$ ) in models (colored dots) and observations (grey crosses). Shown are only values for clear sky and solar zenith angle below $65^{\circ}$
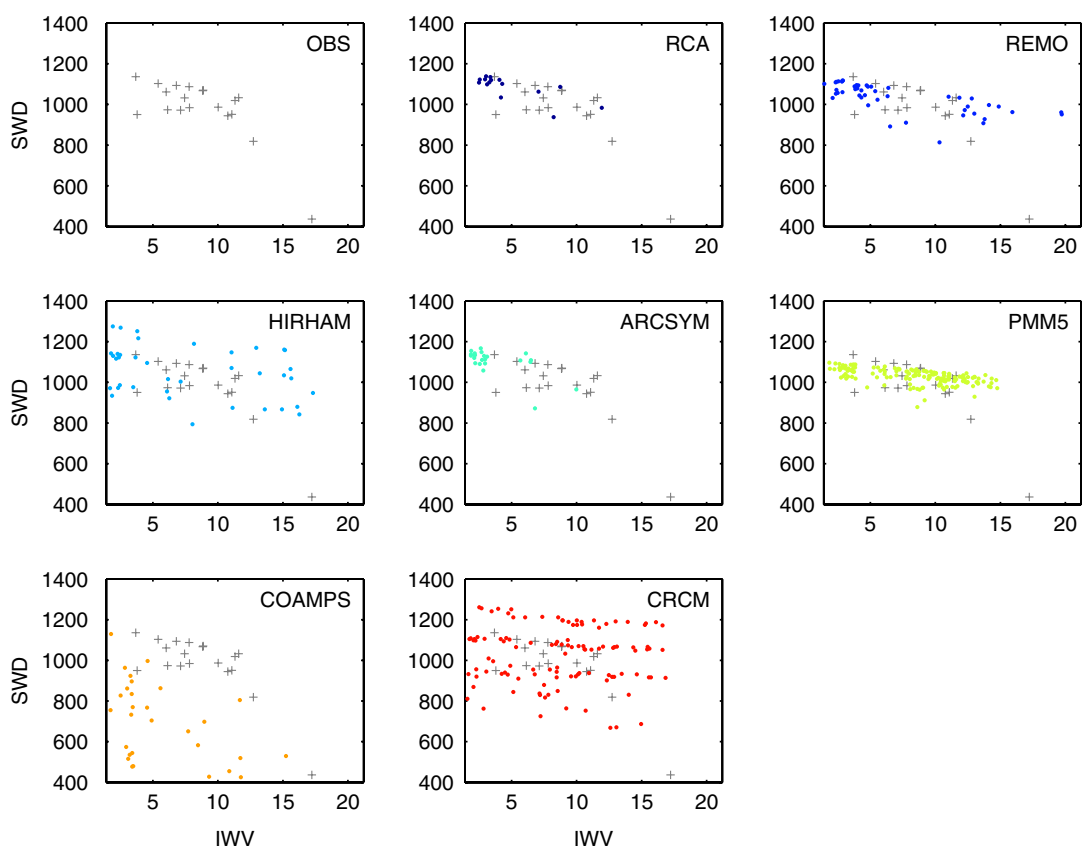

vapour path length traversed by reflected radiation will be significantly longer than for non-reflected radiation. On the other hand, REMO has a similar evolution of the surface albedo but much less scatter than HIRHAM.

Repeating the same graph but for solar zenith angles between 65 and $80^{\circ}$, we find that ARCSYM still reproduces the observed decrease of transmissivity quite well (Fig. 11). The water vapour transmissivity of RCA, REMO, HIRHAM and PMM5 are not sensitive enough to increases in water vapour in this solar zenith angle range. All these models have too much surface SWD when relatively large amounts of water vapour occur in clear-sky conditions. The combination of low solar zenith angle and relatively large amounts of water vapour implies a long water vapour path length for solar radiation. This situation seems to be handled poorly by this set of RCMs. COAMPS $^{\circledR}$ and CRCM show excessive scatter in surface SWD in this solar zenith angle range.

In the Arctic, during spring and fall (ice melt and growth seasons) the solar zenith angle is frequently $>65^{\circ}$ (i.e. the sun is often close to the horizon). In these conditions most models simulate a clear-sky atmosphere that is too transmissive to solar radiation. This error will have negative consequences both for ice melt and growth in these transitions seasons and is a priority problem for improving the performance of climate models in the Arctic.

\subsubsection{Clear-sky LW emissivity and integrated water vapour}

Under clear-sky conditions, surface LWD is mainly a function of near surface temperature and humidity. Since the relative humidity over the Arctic Ocean is always high, air temperature and humidity are closely related. We therefore expect a fairly well defined relationship between integrated water vapour amounts and surface LWD, which is confirmed by the steady decrease in surface LWD as integrated water vapour amounts decrease (Fig. 12). The models capture the general trend with low values of surface LWD when there is little water vapour in the atmosphere (concurrent with cold temperatures) and high LWD in conjunction with high amounts of IWV (warm temperatures). However, there are differences between the models. RCA and COAMPS ${ }^{\circledR}$ agree fairly well with observations for the entire range of IWV. REMO, HIRHAM and CRCM are close to the observations at low IWV values, but their clear-sky LW emissivity becomes too low at large water vapour concentrations. The opposite is found for ARCSYM, with a tendency for surface LWD to exceed observed values at higher water vapour concentrations. The LW emissivity of water vapour in PMM5 appears too low for all values of IWV consistent with a known clear sky bias in LWD for the CCM2 radiation parameterization (Pinto et al. 1999).

The amount of crosses and dots plotted in Figs. 10, 11 and 12 gives an estimate of the number of occurrences of cloud-free conditions in both the observations and the models. The excessive number of clear-sky occurrences in PMM5 and CRCM is consistent with the overall underestimate of cloud amounts seen in Fig. 2. On the other hand, RCA and to a lesser extent ARCSYM underestimate the frequency of occurrence of clear-sky conditions, implying these models overestimate the frequency of cloudy conditions at SHEBA. Both of these models have a reasonable simulation of the annual cycle of monthly mean cloud 
Fig. 11 As Fig. 10 but for solar zenith angles larger than $65^{\circ}$
Fig. 12 Variation of downwelling LWD radiation (in $\mathrm{W} \mathrm{m}^{-2}$ ) with vertically integrated water vapour (in $\mathrm{kg}$ $\mathrm{m}^{-2}$ ) in models (colored dots) and observations (grey crosses). Only clear sky values are shown
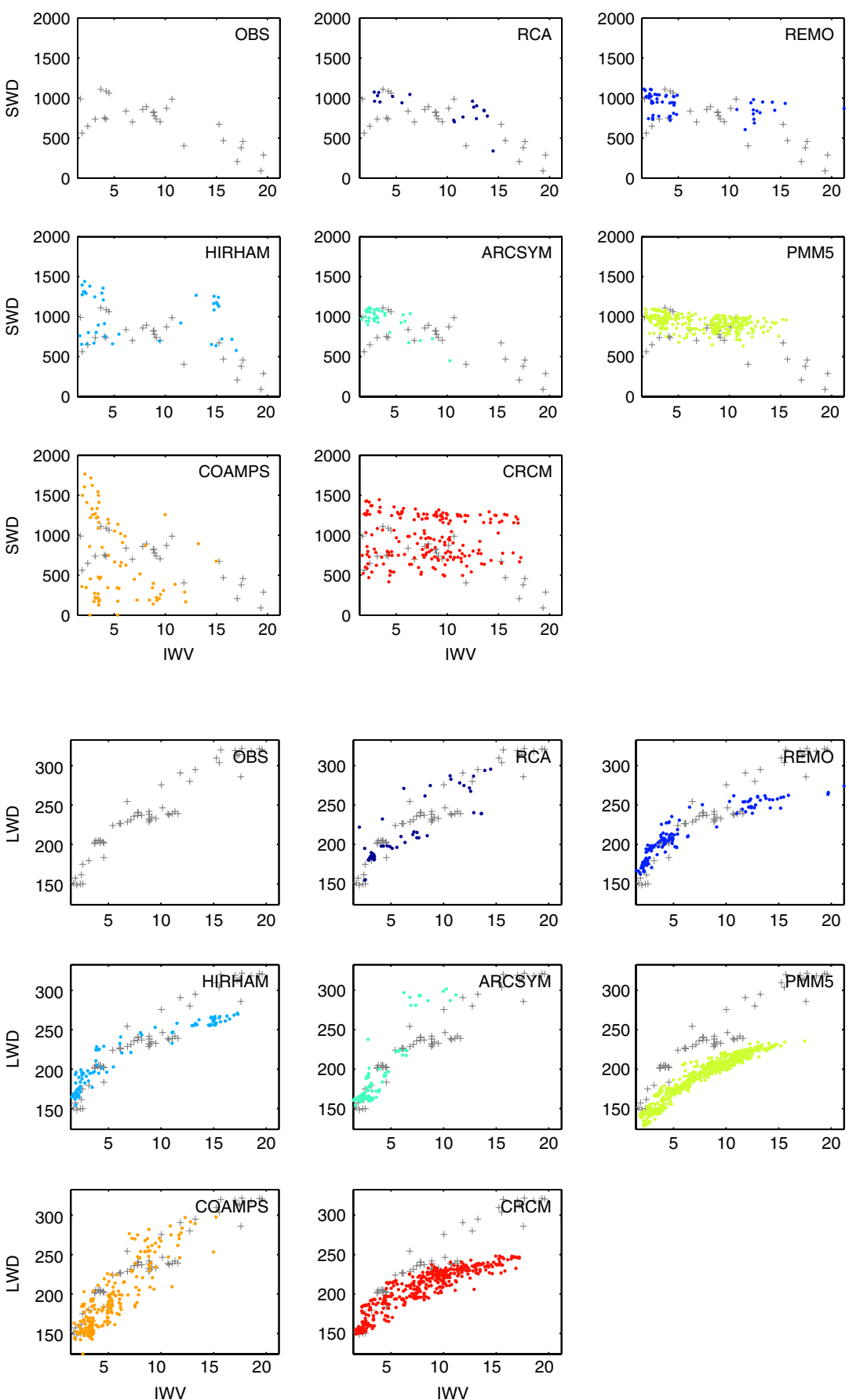

cover at SHEBA (see Fig. 2). Errors in the frequency of occurrence of cloud suggest they may be achieving accurate monthly mean cloud cover amounts from an incorrect frequency distribution of the instantaneous cloud fractions.

\section{Discussion}

Most models simulate the monthly mean surface SWD and LWD at the SHEBA station reasonably accurately. Nev- ertheless, there are a few clear outlier models with respect to the simulated surface radiation budget. We have presented the most likely reasons for these deviations in this paper. Clearly, the surface radiation biases in these outlier models would greatly prejudice their ability to simulate coupled radiation-ice interactions in a fully coupled ocean-atmosphere model. It is, therefore, highly important that systematic errors of this type are addressed.

Despite the relatively good agreement between observed and simulated surface radiation in most models, when it 
comes to the factors controlling radiation-clouds and surface albedo-we find much less agreement between observations and models. The most striking difference is found for the cloud cover. Although the overall average cloud cover of the different models compares reasonably well with observations (or climatology), there is much less skill and inter-model agreement in simulating the higher time variability of cloud cover. The relatively good agreement in simulated surface SWD and LWD suggest that much of the cloud disagreement occurs for optically thin clouds that have a relatively small, but certainly nonnegligible, impact on the surface radiation budget (this being particularly true in the winter). This finding concurs with Wyser and Jones (2005) and further suggests that the disagreement between different Arctic cloud observations is dominated by the varying ability of different cloud sensors to detect optically thin clouds.

A more detailed analysis of daily averaged radiation and cloud cover confirms this picture. Simulated and observed radiation correlate well and biases are relatively small. On the other hand, the daily averaged cloud cover of models and observations are more or less uncorrelated. With respect to the uncertainty in cloud observations due to differing sensor sensitivties, Schweiger et al. (2002) have shown that cloud cover variability from satellites and from the SHEBA station are well correlated at timescales larger than 4 days. We therefore repeated the cloud cover analysis using 5-day averages rather than daily values (results not shown). The correlation coefficient between simulated and observed cloud cover remains below 0.7 for all models, and for five models it is below 0.5 . We therefore conclude that even on longer timescales, where the variability of satellite and surface observed cloud cover agree, the RCMs are still unable to reproduce cloud cover realistically.

Why is the correlation high for observed and modeled SFC radiation, but low for cloud cover? Why is the discrepancy between modeled and observed clouds not reflected in the modeled radiation? Many Arctic clouds are optically thin and contribute only little to the absorption of SW and the emission of LW radiation. Thus, radiation and cloud cover are not necessarily correlated and the frequent occurrence of thin clouds in models may leave no trace in the SFC radiation.

Surface albedo observed at SHEBA varies from $\sim 0.7$ to 0.75 during winter to a mixture of open water and bare seaice values in the middle of the summer $(\sim 0.35)$. Some models capture this evolution, while others have a more or less constant albedo throughout the year. Some models clearly have problems with snow melt, with sea-ice remaining snow covered even in summer. The prescribed lower surface temperature over the Arctic Ocean is always close to the freezing point due to the presence of melting snow and ice during every month of the year. Thus, the lower boundary temperature for all models hardly ever exceeds $0^{\circ} \mathrm{C}$ and RCMs that use the difference between the lowest level temperature and freezing point to melt snow will not work properly. The best way to solve this problem is to implement a more physically based 'snow on sea-ice scheme' that does not rely on temperature differences but rather calculates an energy balance at the surface to compute snow melt. Another factor that needs to be accounted for is melt ponds that can drastically lower the area-averaged albedo.

To understand the physical mechanisms controlling radiative transfer, we investigated the co-variability of radiation with either cloud or humidity variables. Surface SWD decreases with increasing water content in all models, but in most models this decrease is stronger than in the observations. It was suggested that this could be related to problems distinguishing between liquid water and ice in a given cloud. Assuming liquid water when a cloud actually consists of ice will make the cloud less transparent. Another likely cause is too small parameterized values of ice effective radius compared to those observed at SHEBA.

The solar transmissivity of clouds may be too low in most models (Fig. 8), but we cannot exclude the possibility that part of the problem with underestimated surface SWD is due to the poor or absent representation of multiple reflections between the surface and cloud-base. In the models with high surface albedo, the co-variability of surface SWD with cloud water path agrees well with observations. In these models, however, the albedo is too high during summer compared to observations, so the right surface SWD is simulated for the wrong reason. If multiple reflections between the surface and cloud-base were properly accounted for, these models may yield higher values of surface SWD in excess of those observed. The other group of models, with realistic surface albedo, would agree better with the observed SWD if there was an increased contribution of multiple reflections of SW to the total surface downwelling SW radiation. The co-variability plot of cloud water path and SW radiation would then change in favor of the models with lower surface albedo during summer. From this perspective, it is important that cloud-radiation interaction and surface albedo are evaluated concurrently in Arctic climate models so that a correct diagnosis of surface radiation errors can be made.

Observed LW emissivity spans the range between clouds being blackbodies and the equivalent of saturated humid air. The models tend to lie on the high side, with clouds that are "blacker" than observations suggest, in particular for warmer clouds. For cold clouds the LW emissivity remains high in some of the models, while it is close to the lower value for saturated humid air in others. It is possible that the switch from high to low emissivity is related to the phase of cloud particles. In models warm 
(liquid) clouds tend to be treated as blackbodies, while cold (ice) clouds have a much lower emissivity. The comparison with observations shows that such a simple distinction is not justified; there do exist warm clouds with low emissivity and cold clouds with high emissivity.

Besides the cloud phase, the effective radius plays a role in determining cloud emissivity. It is probable that the present parameterizations of effective radius need to be adjusted or further generalized for the Arctic, in particular the effective radius of ice particles. Unfortunately, the effective radius of ice clouds is not easy to access; the basic problem being how to define an effective radius for nonspherical ice crystals, and for a cloud that is composed of many different crystal habits. Data on ice crystal size spectra can be obtained from in-situ measurements, but not from remote sensing instruments unless an ice particle shape is assumed. This limits the amount of available data, and existing parameterizations of the effective radius suffer from large uncertainty. Furthermore, most parameterizations of the ice effective radius have been developed using tropical or mid-latitude cloud data and may therefore not be suitable for the Arctic.

The analysis of radiative transfer under clear sky conditions produced some interesting results. The sensitivity of solar transmissivity to water vapour agrees well with observations, but only for low solar zenith angles. This may again be a manifestation of the fact most RCMs and their radiation schemes have been developed for mid-latitude conditions where errors at high solar zenith angles are relatively unimportant. However, in the Arctic, the sun is often close to the horizon and these model deficiencies will be important. We also speculate about the role of surface albedo in conjunction with the solar zenith angle. The surface albedo in most of the models does not vary as a function of the solar zenith angle. Observations from snowcovered surfaces (Dozier and Painter 2004) suggest there is a dependency of snow albedo on solar zenith angle. A radically different surface albedo at high solar zenith angle will influence simulated surface SWD, by changing the water vapour path length for reflected solar radiation. If snow albedo was higher in models at large solar zenith angles, the relationship between column integrated water vapour and surface SWD shown in Fig. 11 would be changed, with less surface SWD for a given integrated water vapour amount, due to a reflection induced increase in solar path length. It is therefore possible that an improvement in the calculation of surface (snow) albedo at high solar zenith angles may mitigate the problem with clear-sky solar transmissivity identified in Fig. 11.

Surface LWD varies with the amount of water vapour in the atmosphere. All models reproduce the observed behavior at low amounts of water vapour. At high amounts some models still agree with the observations, while others over- or underestimate surface LWD. Possibly, these differences can be attributed to differences in the structure of the planetary boundary layer between models. The majority of surface LWD originates in the lowest layers of the atmosphere. An incorrect temperature or humidity distribution in the boundary layer, or a wrong boundary layer height, will thus change the surface LWD radiation. Tjernström et al. (2005) have shown that differences in the PBL structure between the ARCMIP models is more pronounced in summer than in winter. During summer the input of solar radiation is higher, leads open in the sea-ice boosting evaporation, and a more stochastic, convective regime replaces the stable regime that prevailed during winter.

\section{Conclusions}

Eight regional climate models have been used to simulate one year of Arctic climate at the SHEBA site. Initial and boundary conditions were identical for all models, and the model domain was chosen to be relatively small and centred on the SHEBA station. Differences between the model simulations can thus be attributed to different model formulations and their representation of physical processes. We have evaluated the surface radiation budget against high-quality observations at SHEBA. We have further investigated the processes controlling the underlying performance of RCMs with respect to cloud cover and surface radiation. We do this because cloud and radiation processes are the main controls on sea-ice evolution in the Arctic. In coupled Arctic atmosphere-ocean-ice climate models it is crucial that sea-ice evolution is simulated accurately and in a physically realistic manner. A prerequisite to this is a realistic simulation of cloud and radiation processes. We can only have confidence in future predictions of the response of Arctic sea-ice to changing atmospheric composition (the sea-ice/snow albedo feedback) if we are confident the underlying physical processes controlling this response are well simulated.

The observed surface radiation on monthly and daily timescales is reasonably well reproduced by the ensemble of all RCMs, despite some apparent variability between the different models. However, when it comes to the atmospheric variables that control radiative transfer, the agreement between models and observations is not so good. Cloud cover in the RCMs is more or less uncorrelated with observations on a daily basis. Even in the monthly average, many models do not reproduce the annual cycle properly, and the disagreement between models is large. From this we would expect a worse representation of the surface radiation budget than what we actually find. Most likely, some model deficits have been "tuned away", for example 
compensating errors in cloud transmissivity and cloud cover. Every climate model requires some tuning, and getting the surface radiation right assures that an important component of the surface energy budget is correct. Nevertheless, an effort should be paid to improve the parameterizations of cloud cover, surface albedo and solar transmissivity to better match the observations, thereby more faithfully representing the key physics controlling the Arctic surface radiation.

None of the models stands out as being superior to the others. PMM5 has an obvious problem with too few clouds throughout the simulation, resulting in too much surface SWD and too little LWD. The models fall into two groups when looking at surface albedo in summer. One group shows only a small variation compared to winter, while the other better follows the observed evolution of surface albedo. Interestingly, the group of models with too high surface albedo agrees better with the observed surface SWD, which could be explained by a too low contribution from multiple reflections between the surface and clouds. There is, however, also a strong suggestion that the second group of models, with a negative bias in surface SWD, have cloud albedos that are systematically too high across the range of observed LWP. Finally, a problem was identified in representing clear-sky solar radiative transfer at high solar zenith angles. It is not completely clear whether this is directly due to deficiencies in the treatment of water vapour in the solar radiation schemes or results from a poor parameterization of snow and sea-ice albedo at high solar zenith angles.

Future simulations made within the ARCMIP project will evaluate improvements made to parameterizations in the light of these findings and subsequently test these improvements in coupled Arctic RCMs, where sea-ice and SSTs are free to respond to the simulated surface radiation.

Acknowledgments We thank our colleagues in the SHEBA Atmospheric Surface Flux Group, Ed Andreas, Chris Fairall, Peter Guest, and Ola Persson for help collecting and processing the data. The National Science Foundation supported this research with grants to the U.S. Army Cold Regions Research and Engineering Laboratory, NOAA's Environmental Technology Laboratory, and the Naval Postgraduate School. This study was patially supported by the EU project GLIMPSE (EVK2-CT-2002-00164) (K. Wyser, U.Willen, J.H. Christensen, K. Dethloff, J.E. Haugen, M. Køltzow and A. Rinke), by the Canadian Foundation for Climate and Atmospheric Science (CFCAS), grant number CRDP256319 in support of the CRCM Network (P. Du, E. Girard, C.G. Jones and R. Laprise) and by NSF grant OPP-0229649 (J. Cassano and M.J. Shaw).

\section{References}

Bromwich DH, Cassano JJ, Klein T, Heinemann G, Hines KM, Steffen K, Box JE (2001) Mesoscale modeling of katabatic winds over Greenland with the Polar MM5. Mon Wea Rev 129:2290-2309
Cassano JK, Box JE, Bromwich DH, Li L, Steffen K (2001) Evaluation of polar MM5 simulations of Greenlands' atmospheric circulation. J Geophys Res 106:33867-33890

Caya D, Laprise R (1999) A semi-implicit semi-Lagrangian regional climate model: the Canadian RCM. Mon Wea Rev 127:341-362

Chen B, Bromwich DH, Hines KM, Pan X (1995) Simulations of the 1979-1988 polar climates by global climate models. Ann Glaciol 21:85-90

Christensen JH, Christensen OB, Lopez P, van Meijgaard E, Botzet M (1996) The HIRHAM4 regional atmospheric climate model. DMI Sci. Rep. 96-4, Dan. Meteorol Inst, Copenhagen, 51pp

Christensen JH, Machenhauer B, Jones RG, Schar C, Ruti PM, Castro M Visconti G (1997) Validation of present-day regional climate simulations over Europe: LAM simulations with observed boundary conditions. Clim Dyn 13:489-506

Christensen JH, Kuhry P (2000) High resolution regional climate model validation and permfrost simulation for the East-European Russian Arctic. J Geophys Res 105:29647-29658

Comiso, J (2002) Bootstrap sea ice concentrations for NIMBUS-7 SMMR and DMSP SSM/I. National Snow and Ice Data Center, Boulder, CO, USA, Digital media

Curry JA, Meyers FG, Radke LF, Brock CA, Ebert E (1990) Occurrence and characteristics of lower tropospheric ice crystals in the Arctic. Int J Climatol 10:749-764

Curry JA, Schramm JL, Ebert EE (1993) Impact of clouds on the surface radiation balance of the Arctic Ocean. Meteorol Atmos Phys 51:197-217

Curry JA, Coauthors (2000) FIRE Arctic clouds experiment. Bull Amer Meteorol Soc 81:5-29

Curry JA, Schramm JL, Perovich DK, Pinto JO (2001) Applications of SHEBA/FIRE data to evaluation of snow/ice albedo parameterizations. J Geophys Res 106:15345-15355

Curry JA, Lynch AH (2002) Comparing arctic regional climate models. EOS Trans Amer Geophys Union 83:87

Dethloff K, Rinke A, Lehmann R, Christensen JH, Botzet M, Machenhauer B (1996) A regional climate model of the Arctic atmosphere. J Geophys Res 101:23401-23422

Dickinson RE, Errico R, Giorgi F, Bates GT (1989) A regional climate model for the western United States. Clim Change 15:383-422

Douville H, Royer J-F, Mahfouf J-J (1995) A new snow parameterization for the Meteo-France climate model. Clim Dyn 12:21-35

Dozier J, Painter TH (2004) Multispectral and hyperspectral remote sensing of alpine snow properties. Ann Rev Earth Planet Sci 32:465-494

Duynkerke PG, De Roode SR, van Zanten MC, Calvo J, Cuxart J, Cheinet S, Chlond A, Grenier H, Jonker PJ, Kohler M, Lenderink G, Llewellen D, Lappen C-L, Lock AP, Moeng C-H, Muller F, Olmeda D, Pirou J-M, Sanchez E, Sednev I (2004) Observations and numerical simulations of the diurnal cycle of the EUROCS stratocumulus case. Quart J Royal Met Soc 130(604):3260-3297

Fowler C, Maslanik J, Haran T, Scambos T, Key J, Emery W (2000) updated 2002: AVHRR Polar Pathfinder twice-daily $5 \mathrm{~km}$ easegrid composites. National Snow and Ice Data Center, Boulder. Digital media see http://www.nsidc.org/data/nsidc-0066.html

Fouquart Y, Bonnel B (1980) Computation of solar heating of the Earth's atmosphere: a new parameterization. Beitr Phys Atmos 53:35-62

Giorgi F, Mearns LO (1999) Introduction to the special section: regional climate modelling revisited. J Geophys Res 104:6335-6352

Girard E, Blanchet J-P (2001) Microphysical parameterization of Arctic diamond dust, ice fog, and thin stratus for climate model. J Atmos Sci 58:1181-1198

Hack JJ, Boville BA, Briegleb BP, Kiehl JT, Rasch PJ, Williamson DL: (1993) Description of the NCAR Community Climate Model (CCM2), NCAR Technical Note, NCAR TN-382+STR, 120pp 
Harshvardhan RD, Randall DA, Corsetti TG (1987) A fast radiation parameterization for atmospheric circulation models. J Geophys Res 92:1009-1016

Heymsfield AJ, Miloshevich LM (2003) Parameterization for the cross-sectional area and extinction of cirrus and stratiform ice cloud particles. J Atmos Sci 60:936-956

Hodur RM (1997) The Naval Research Laboratory's coupled ocean/ atmosphere mesoscale prediction systems $\left(\right.$ COAMPS $\left.^{\circledR}\right)$. Mon Wea Rev 125:1414-1430

Hsie EY, Anthes RA, Keeyser D (1984) Numerical simulation of frontogenesis in a moist atmosphere. J Atmos Sci 41:2581-2594

Intrieri JM, Shupe MD, Uttal T, McCarty BJ (2002a) An annual cycle of Arctic cloud characteristics observed by radar and lidar at SHEBA. J Geophys Res 107(C10):8030

Intrieri JM, Fairall CW, Shupe MD, Persson POG, Andreas EL, Guest PS, Moritz RE (2002b) An annual cycle of Arctic surface cloud forcing at SHEBA. J Geophys Res 107(C10):8039

Intrieri JM, Shupe MD, Uttal T, McCarty BJ (2002c) Arctic cloud statistics from lidar and radar at SHEBA. J Geophys Res 107:8030-8039

Jacob D (2001) A note to the simulation of annual and interannual variability of the water budget over the Baltic Sea drainage basin. Meteorol Atmos Phys 77:61-73

Jones RG, Murphy JM, Nouger M (1995) Simulation of climate change over Europe using a nested regional-climate model. Part I: Assessment of control climate including sensitivity to location of lateral boundaries. Quart J Roy Met Soc 121:1413-1449

Jones CG, Willen U, Ullerstig A, Hansson U (2004a) The Rossby Centre regional atmospheric climate model (RCA) Part I: Model climatology and performance characteristics for the present climate over Europe Ambio 33:199-210

Jones CG, Wyser K, Ullerstig A, Willen U (2004b) The Rossby Centre regional atmospheric climate model (RCA) Part II: Application to the Arctic climate. Ambio 33:211-220

Karlsson K-G, Willen U, Jones CG, Wyser K (2006) Evaluation of regional cloud climate simulations using a ten-year NOAA AVHRR cloud climatology. Part I: Compensating for limitations in observation capabilities. J Geophys Res (submitted)

Key JR, Barry RG (1990) Cloud cover analysis over the Arctic with the advanced very high resolution radiometer: cloud detection. $\mathrm{J}$ Geophys Res 94:8521-8535

Key JR (2001) The Cloud and Surface Parameter Retrieval (CASPR) System for Polar AVHRR Data User's Guide. Space Science and Engineering Center, University of Wisconsin, Madison, 62pp

Key JR (2002) The cloud and surface parameter retrieval (CASPR) system for polar AVHRR, Part II: Reference. NOAA/NESDIS/ ORA/ARAD/ASPT, Madison. Available from http://www.stratus.ssec.wisc.edu/caspr/refman.pdf

Laprise R, Caya D, Giguère M, Bergeron G, Côté H, Blanchet J-P, Boer GJ, McFarlane N (1998) Climate and climate change in Western Canada as simulated by the Canadian regional climate model. Atmos Ocean 36(2):119-167

Lenderink G, Siebesma AP, Cheinet S, Irons S, Jones CG, Marquet P, Muller F, Olmeda D, Calvo J, Sánchez E, Soares P (2004) The diurnal cycle of shallow Cumulus clouds over land: a single column model intercomparison study. Quart J Roy Met Soc 130(604):3339-3364

Liljegren JC (1999) Observations of integrated water vapour and cloud liquid water at the SHEBA ice station. In: Pampaloni P, Paloscia S (eds) Microwave radiometry and remote sensing of the earth's surface and atmosphere. VSP Press, pp 155-163.Available from http://www.arm.gov/docs/instruments/publications/mwrsheba.pdf

Lynch AH, Chapman WL, Walsh JE, Weller G (1995) Development of a regional climate model of the Western Arctic. J Clim 8:1555-1570
Lynch AH, Maslanik JA, Wu W (2001) Mechanisms in the development of anomalous sea ice extent in the western Arctic: a case study. J Geophys Res 106:28097-28105

McFarlane NA (1998) Climate and climate change in Western Canada as simulated by the Canadian Regional Climate Model. Atmos 36(2):119-167

McFarlane NA, Boer GJ, Blanchet J-P, Lazare M (1992) The Canadian climate centre second generation general circulation model and its equilibrium climate. J Clim 5:1013-1044

McFarquhar GM, Heymsfield AJ (1998) The definition and significance of an effective radius for ice clouds. J Atmos Sci 55:2039-2052

McGregor JL (1997) Regional climate modelling. Meteorol Atmos Phys 63:105-117

Mlawer EJ, Taubman SJ, Brown PD, Iacano MJ, Clough SA (1997) Radiative transfer for inhomogenous atmospheres: RRTM, a validated correlated-K model for the longwave. J Geophys Res 102:16663-16682

Morcrette J-J (1984) Sur la paramétrisation du rayonnement dans les modèles de la circulation générale atmosphérique. Thèse de docotorat, Université des sciences et techniques de Lille, 373 pp

Niemelä S, Räisänen P, Savijärvi H (2001) Comparison of surface radiative flux parameterizations. Part I: Longwave radiation. Atmos Res 58:1-18

Pedersen CA, Winther J-C (2005) Intercomparison and validation of snow albedo parameterization schemes in climate models. Clim Dyn 25:351-362

Perovich DK (1998) The optical properties of sea-ice. In: Physics of Ice Covered Seas. Lepparanta M (ed). Helsinki University Printing House, Helsinki

Perovich DK, Tucker WB III, Ligett KA (2002) Aerial observations of the evolution of ice surface conditions during summer. J Geophys Res 107(C10):8048

Persson POG, Fairall CW, Andreas EL, Guest PS, Perovich DK (2002) Measurements near the atmospheric surface flux group tower at SHEBA: near surface conditions and surface energy budget. J Geophys Res 107(C10):8045

Pinto JO, Curry JA, Fairall CW (1997) Radiative characteristics of the Arctic atmosphere during spring as inferred from ground-based measurements. J Geophys Res 102:6941-6952

Pinto JO, Curry JA, Lynch AH, Persson POG (1999) Modeling clouds and radiation for the November 1997 period of SHEBA using a column climate model. J Geophys Res 104:6661-6678

Rasch PJ, Kristjansson JE (1998) A comparison of the CCM3 model climate using diagnosed and predicted condensate parameterisations J Clim 25:1587-1614

Reisner J, Rasmussen RM, Bruintjes RT (1998) Explicit forecasting of supercooled liquid water in winter storms using the MM5 mesoscale model. Quart J Roy Met Soc 124:1071-1107

Rinke A, Dethloff K, Christensen JH , Botzet M, Machenhauer B (1997) Simulation and validation of Arctic radiation and clouds in a regional climate model. J Geophys Res 102:29833-29847

Rinke A, Dethloff K, Cassano J, Christensen JH, Curry JA, Du P, Girard E, Haugen J-E, Jacob D, Jones CG, Køltzow M, Laprise R, Lynch AH, Pfeifer S, Serreze MC, Shaw MJ, Tjernström M, Wyser K, Žagar M (2006) Evaluation of an ensemble of Arctic regional climate models: spatial patterns and height profiles. Clim Dyn. doi:10.1007/s00382-005-0095-3

Roeckner E, Arpe K, Bengtsson L, Christoph M, Claussen M, Dumenil L, Esch M, Giorgetta M, Schlese U, Schulzweida U (1996) The atmospheric general circulation model \{ECHAM-4\}: model description and simulation of present-day climate, Report no.218, Max-Planck-Institut fur Meteorologie, Hamburg

Rutledge SA, Hobbs PV (1983) The mesoscale and microscale structure and organization of clouds and precipitation in 
midlatitude cyclones. VIII: A model for the "Seeder-Feeder" Process in Warm-Frontal Rainbands. J Atmos Sci 40:1185-1206

Sass BH, Rontu L, Savijärvi H, Räisänen P (1994) HIRLAM-2 Radiation scheme: Documentation and tests. HIRLAM Technical Report No 16, SMHI, SE-601 76 Norrköping, Sweden, 43 pp Schweiger AJ, Lindsay RW, Francis JA, Key J, Intrieri JM, Shupe MD (2002) Validation of TOVS Path-P data during SHEBA. J Geophys Res 107:8041

Serreze MC, Kahl JD, Schnell RC (1992) Low-level temperature inversions of the Eurasian Arctic and comparisons with Soviet drifting station data. J Clim 5:615-629

Shupe MD, Uttal T, Matrosov SY, Frisch AS (2001) Cloud water contents and hydrometeor sizes during the FIRE Arctic clouds experiment. J Geophys Res 106:15015-15028

Shupe MD, Matrosov SY, Uttal T (2006) Arctic mixed-phase cloud properties from surface-based sensors at SHEBA. J Atmos Sci 63:697-711

Sorteberg A, Katsov V, Walsh J, Palova T (2007) The Arctic surface energy budget as simulated with the IPCC AR4 AOGCMs. Clim Dyn. doi:10.1007/s00382-006-0222-9

Tao X, Walsh JE, Chapman WL (1996) An assessment of global climate model simulations of Arctic air temperatures. J.Clim 9:1060-1076

Thorndike A (1992) A toy model linking atmospheric thermal radiation and sea ice growth J Geophys Res 97:9401-9410
Tjernström M, Zagar M, Svensson G, Cassano J, Pfeifer S, Rinke A, Wyser K, Dethloff K, Jones C, Semmler T, Shaw M (2005) Modelling the arctic boundary layer: an evaluation of six ARCMIP regional-scale models using data from the SHEBA project. Boundary Layer Meteorol 117(2):337-381. doi:10.1007/ s10546-004-7954-Z

Uttal T et al (2002) Surface heat budget of the Arctic Ocean Bull Am Meteorol Soc 83:255-275

Verseghy DL (1991) CLASS - a Canadian land surface scheme for GCMs Part I: soil model. Int J Climatol 11:111-133

Walsh JE, Kattsov VM, Chapman WL, Govorkova V, Pavlova T (2002) Comparison of Arctic climate simulations by uncoupled and coupled global models. J Clim 15:1429-1446

Westwater ER, Han Y, Shupe MD, Matrosov SY (2001) Analysis of integrated cloud liquid and precipitable water vapour retrievals from microwave radiometers during SHEBA. J Geophys Res 106:32019-32030

Wild M, Ohmura A, Gilgen H, Morcrette JJ, Slingo A (2001) Downward longwave radiation in general circulation models. J Clim 14:3227-3239

Wyser K, Jones CG (2005) Modeled and observed clouds during surface heat budget of the Arctic Ocean (SHEBA). J Geophys Res 110:D09207. doi:10.1029/2004JD004751 